\title{
Primary Modes of Global Drop Size Distributions ${ }^{\mathscr{O}}$
}

\author{
B. Dolan, B. Fuchs, S. A. Rutledge, and E. A. Barnes \\ Department of Atmospheric Science, Colorado State University, Fort Collins, Colorado \\ E. J. THOMPSON \\ Applied Physics Laboratory, University of Washington, Seattle, Washington
}

(Manuscript received 18 August 2017, in final form 30 December 2017)

\begin{abstract}
Understanding drop size distribution (DSD) variability has important implications for remote sensing and numerical modeling applications. Twelve disdrometer datasets across three latitude bands are analyzed in this study, spanning a broad range of precipitation regimes: light rain, orographic, deep convective, organized midlatitude, and tropical oceanic. Principal component analysis (PCA) is used to reveal comprehensive modes of global DSD spatial and temporal variability. Although the locations contain different distributions of individual DSD parameters, all locations are found to have the same modes of variability. Based on PCA, six groups of points with unique DSD characteristics emerge. The physical processes that underpin these groups are revealed through supporting radar observations. Group 1 (group 2) is characterized by high (low) liquid water content (LWC), broad (narrow) distribution widths, and large (small) median drop diameters $D_{0}$. Radar analysis identifies group 1 (group 2) as convective (stratiform) rainfall. Group 3 is characterized by weak, shallow radar echoes and large concentrations of small drops, indicative of warm rain showers. Group 4 identifies heavy stratiform precipitation. The low latitudes exhibit distinct bimodal distributions of the normalized intercept parameter $N_{w}, \mathrm{LWC}$, and $D_{0}$ and are found to have a clustering of points (group 5) with high rain rates, large $N_{w}$, and moderate $D_{0}$, a signature of robust warm rain processes. A distinct group associated with ice-based convection (group 6) emerges in the midlatitudes. Although all locations exhibit the same covariance of parameters associated with these groups, it is likely that the physical processes responsible for shaping the DSDs vary as a function of location.
\end{abstract}

\section{Introduction}

Understanding the variability of drop size distributions (DSDs) around the globe is important for remote sensing of precipitation, retrieving distributions of latent heating, and parameterizing microphysical processes in numerical models. Remote sensing retrievals routinely make assumptions about DSDs to relate observations to physical quantities (Munchak et al. 2012). For example, the DSD fundamentally determines the relationship between radar reflectivity $Z$ and rainfall $R$, with individual relationships varying with location and storm type (e.g., Battan 1973;

\footnotetext{
Supplemental information related to this paper is available at the Journals Online website: https://doi.org/10.1175/JAS-D-170242.s1.
}

\footnotetext{
Corresponding author: Brenda Dolan, bdolan@atmos.colostate. edu
}

Atlas et al. 1999; Ulbrich and Atlas 2007). Additionally, many bulk numerical model parameterizations employ two-moment microphysical schemes where the number concentration and mass mixing ratio of each hydrometeor type are predicted and mean size is diagnosed, thus requiring that a fixed shape parameter $\mu$ be assumed if a gamma distribution is used (e.g., Meyers et al. 1997; Saleeby and Cotton 2004). However, $\mu$ assumptions may introduce undesirable effects regarding the development of precipitation (Uijlenhoet et al. 2003; Milbrandt and Yau 2005).

DSD variability is determined by cloud-scale processes as well as environmental characteristics (Cotton et al. 2011). For example, in convection, strong updrafts can lead to supercooled liquid water in the mixed-phase region, thereby promoting the growth of graupel and hail via accretion. Upon melting, large drops are formed, which may fall out or undergo additional coalescence growth below the melting level. Evaporation may occur 
below cloud base, which preferentially removes smaller drops. In contrast, weak vertical motions in stratiform precipitation allow for ice crystals to grow initially via deposition followed by aggregation and possibly riming (Rutledge and Houze 1987; Houze 1997).

Previous studies have investigated DSDs in different locations around the world. Bringi et al. (2003, 2009, hereafter BR03, BR09) initially separated disdrometer data into convective and stratiform DSDs using a threshold on the standard deviation of the rain rate (over five consecutive 2-min samples). Distinct clustering was identified within the parameter space of the massweighted mean diameter $D_{m}$ and normalized intercept $N_{w}$. The clusters were identified as continental and maritime convection as well as stratiform rain. BR09 also found the same convective and stratiform clusters of DSD parameters when $D_{m}$ and $N_{w}$ were derived from polarimetric radar, leading to the rendering of a continuous separator line for segregating convective and stratiform rain. Previous studies have noted a significant overlap between convective and stratiform populations in $Z-R$ space at low $R$, suggesting that a true separation between these rain types requires additional parameters (Yuter and Houze 2002; Atlas et al. 2000).

Thompson et al. (2015, hereafter T15) built upon these studies by investigating tropical oceanic rainfall and found that while stratiform populations were similar to other regimes, convective precipitation had high $N_{w}$ but relatively low median drop diameters $D_{0}$. This is in contrast with continental convective regimes, which can attain larger $D_{0}$ at lower $N_{w}$ (Atlas and Ulbrich 2000; BR03; Ulbrich and Atlas 2007; BR09; Thurai et al. 2010). For instance, ubiquitous shallow, weak convection identified by $\mathrm{T} 15$ over the tropical oceans did not conform to the BR09 convective-stratiform (C-S) separation line, which was derived from continental and coastal rain samples. T15 determined an updated C-S line for the tropical oceanic regime defined by constant normalized number concentration $\log N_{w}$.

The goal of this study is to examine a larger, global disdrometer dataset to investigate DSD variability in space and time and place some of the previous findings in a larger context. (Most of the studies reviewed above focused on specific locations and/or regimes, thereby limiting generalizations of their findings.) To this end, we employ the statistical analysis technique of principal component analysis (PCA) to help interpret and understand trends in the data. PCA is a powerful tool for analyzing large and complex datasets because it yields the most significant modes of variability in a dataset without requiring any a priori information. PCA is commonly used in climate analysis to reveal spatial relationships or patterns in atmospheric quantities, but it has also been applied to investigate the variability of DSDs relative to environmental variables (Munchak et al. 2012). Hannachi et al. (2007) provides a detailed discussion on the various uses of PCA in atmospheric science.

This study describes the results of applying PCA to a large disdrometer dataset from diverse locations across the globe, ranging from low to high latitudes, including continental and maritime rainfall. The datasets and PCA methodology are outlined in section 2. The different locations are compared, and the results of the PCA are presented in section 3. Polarimetric radar data are used to attribute physical processes to six distinct groups resulting from the PCA. The overall results are discussed and synthesized in section 4 .

\section{Methodology}

\section{a. Disdrometer datasets}

Recent campaigns by the Department of Energy (DOE) Atmospheric Radiation Measurement (ARM) Program (Ackerman and Stokes 2003) and the National Aeronautics and Space Administration (NASA) Global Precipitation Measurement (GPM; Hou et al. 2014) ground validation $(\mathrm{GV})$ program have greatly expanded DSD observations globally. We have compiled 12 disdrometer datasets from diverse locations and meteorological regimes, spanning from the tropics to the high latitudes, that are supported by polarimetric radar observations (Table 1). Two-dimensional video disdrometer (2DVD) datasets from tropical ocean (Manus Island, Papua New Guinea, and Gan Island, Maldives), tropical coastal (Darwin, Northern Territory, Australia), midlatitude continental [Southern Great Plains (SGP)], and high-latitude continental (Finland) locations were provided by the DOE ARM program. These datasets were collected in collaboration with several DOE field campaigns: Tropical Warm Pool-International Cloud Experiment (TWP-ICE) in 2006 (Darwin), ARM MJO Investigation Experiment (AMIE) in 2011 (Gan and Manus Islands), and Biogenic Aerosols-Effects on Clouds and Climate (BAECC) in a high-latitude boreal forest (Finland). Collocated disdrometer and polarimetric radar datasets from coastal orographic high-latitude, continental high-latitude, midlatitude orographic, and midlatitude continental locations were provided by five recent NASA GV experiments [Light Precipitation Validation Experiment (LPVEx): Finland; Midlatitude Continental Clouds and Convection Experiment (MC3E): Great Plains; Iowa Flood Studies (IFloodS): Iowa; Integrated Precipitation and Hydrology Experiment (IPHEx): southern Appalachian Mountains; and Olympic 


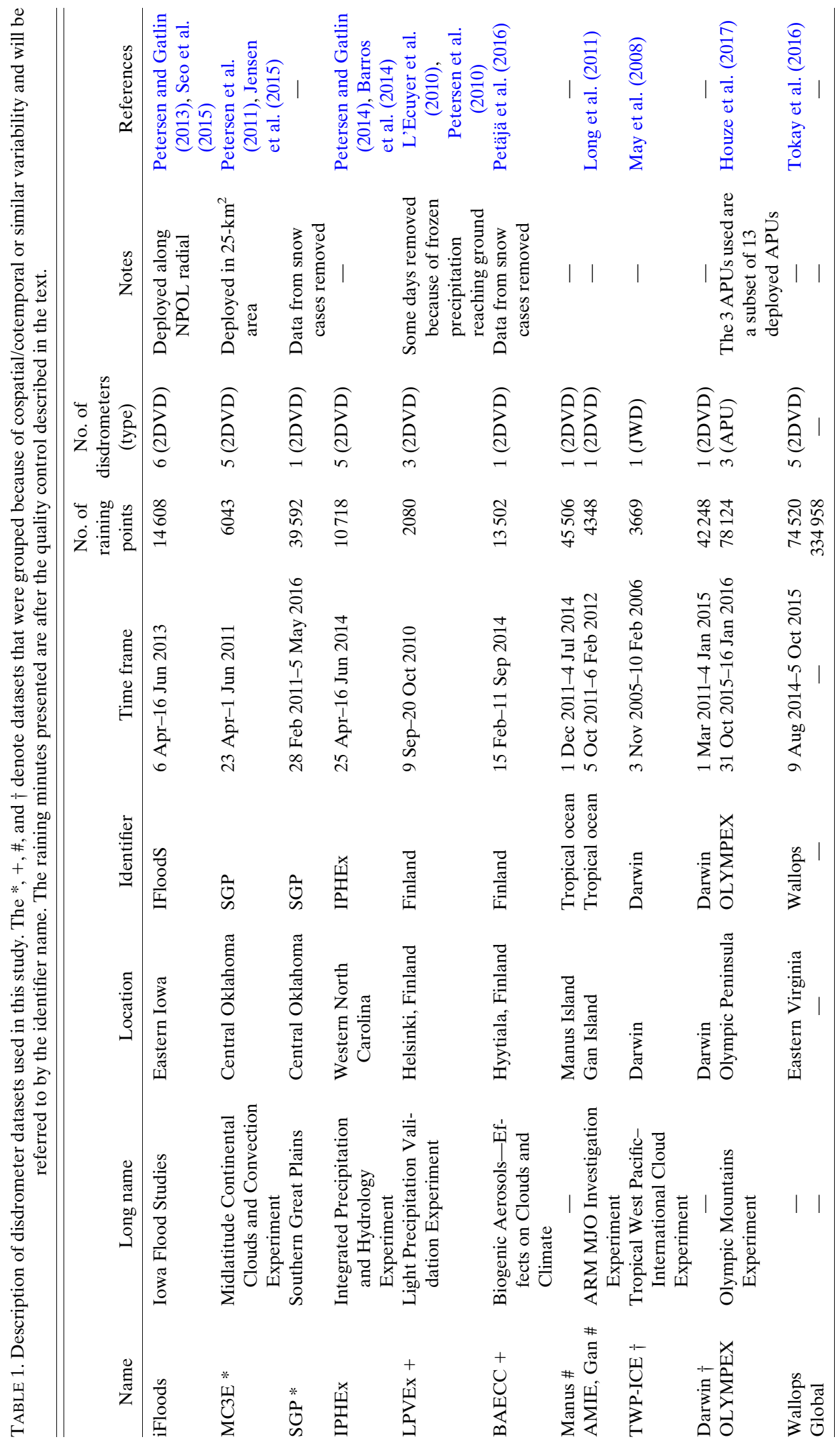




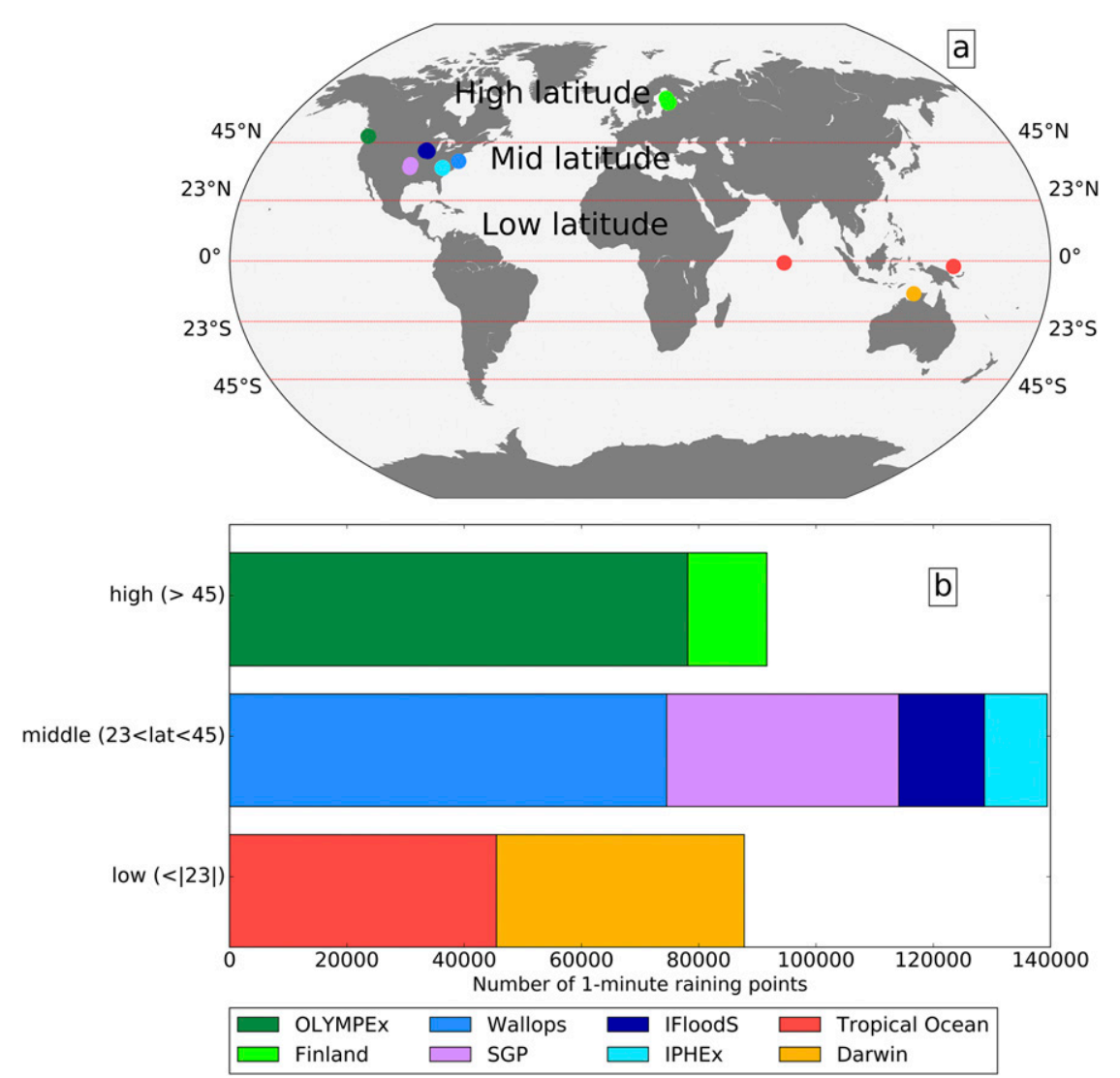

FIG. 1. (a) Locations of disdrometer observations used herein. See Table 1 for individual datasets that fit into the larger eight locations. (b) Distribution of raining minutes as a function of latitude band.

Mountains Experiment (OLYMPEX): Washington State). Additionally, a midlatitude coastal disdrometer dataset was collected at NASA Wallops Island, Virginia. The locations of the datasets are shown in Fig. 1, and a summary of the data and experiments is given in Table 1. These datasets ranged in length from six weeks (LPVEx) to five years (SGP) and sampled from 2080 raining minutes $(\sim 35 \mathrm{~h}$; LPVEx $)$ to 78124 raining minutes $(\sim 1300 \mathrm{~h}$; OLYMPEX). ${ }^{1}$ While the NASA GV experiments deployed several instruments to sample spatial variability, all raining minutes from all described instruments are considered together for each campaign. Field campaign data from the same geographic location and/or time are grouped with corresponding longer-term datasets, resulting in eight datasets: IFloodS, SGP, IPHEx, Finland,

\footnotetext{
${ }^{1}$ In OLYMPEX, 13 Parsivels were deployed at various topographic heights. The entire dataset is over 300000 raining minutes, larger than all the other datasets combined. Therefore, we selected three APUs with minimal contamination from frozen precipitation (Fish Hatchery, Amanda Park, and Bishop Field) for the analysis.
}

tropical ocean, Darwin, OLYMPEX, and Wallops. For ease of discussion and analysis herein, data have been grouped by latitude (Fig. 1): high $\left(\geq 45^{\circ}\right)$, middle $\left(23^{\circ}-45^{\circ}\right)$, and low $\left(\leq 23^{\circ}\right)$, based on the similarities between datasets in common latitude bands (not shown). This grouping results in approximately 90000 raining minutes in the high and low latitudes and $150000 \mathrm{~min}$ in the midlatitudes, with each band comprising both field experiments and longterm installations.

Most of the observations used are derived from a 2DVD (Schönhuber et al. 2008), which uses perpendicular lasers to image drops that fall through the square catchment area $\left(100 \mathrm{~cm}^{2}\right)$. During TWP-ICE, a Joss-Waldvogel impact disdrometer (JWD) was used (Joss and Waldvogel 1967). During OLYMPEX, five 2DVDs were deployed along with 13 automated Parsivel units (APU; Battaglia et al. 2010). During OLYMPEX, the 2DVDs were found to undersample the number of drops because of high drop concentrations in this complex orographic environment. For this reason, we opted to use the APU optical disdrometers for OLYMPEX. 
Following the methodology in T15, 1-min data in every location were thresholded on the total number of drops $(>100)$ and rain rate $\left(>0.05 \mathrm{~mm} \mathrm{~h}^{-1}\right)$. This threshold removed on average $30 \%$ of the data but less than $1 \%$ of the total rainfall (the drop count threshold was responsible for the removal of most observations). These thresholds help prevent small sample sizes from skewing DSD estimates (Smith et al. 1993; Smith 2016). The 2DVDs directly measure liquid water content (LWC; $\left.\mathrm{g} \mathrm{m}^{-3}\right)$ and rain rate $R\left(\mathrm{~mm} \mathrm{~h}^{-1}\right)$, while an empirical fall speed relationship is used for the JWD and APUs to obtain LWC and $R$ (Tokay et al. 2001). A "deadtime correction" (Sheppard and Joe 1994) was applied to the JWD data to account for recovery time of the instrument transducer following drop impacts (Williams et al. 2000). Although it would be ideal to have common platforms across all locations, the availability of these datasets necessitates using three different instruments. Despite different limitations of each instrument such as limited drop sizes (JWD), overestimates of drop size in heavy rain (Parsivels), and beam mismatch (2DVD), previous studies have analyzed the comparative performance of JWDs, 2DVDs, and Parsivels and generally found agreement in distribution fits and integrated parameters (e.g., Tokay et al. 2001; Thurai et al. 2011). We performed a sensitivity study (not shown) where analysis with collocated instruments (e.g., 2DVD and APU in OLYMPEX) confirms that the results presented herein do not significantly change based on instrument choice.

The mass spectrum can be derived directly from disdrometer measurements (Williams et al. 2014):

$$
m(D)=\frac{\pi}{6 \times 10^{3}} \rho_{w} N(D) D^{3},
$$

where $N(D)$ is measured by the disdrometer as a function of the size bins and $\rho_{w}$ is the density of water $\left(\mathrm{g} \mathrm{cm}^{-3}\right)$. The rain DSD can then be described by the mean mass diameter $D_{m}$, which is the first moment of the mass spectrum, and the mass standard deviation $\sigma_{m}$, the square root of the second moment, which represents the breadth of the mass spectrum. For more details of this formulation, see Williams et al. (2014).

Rain DSDs have often been described with a modified gamma distribution (Ulbrich 1983), which is nominally defined by an intercept, median size, and shape factor that describes the breadth and slope of the distribution. A special case of the four-parameter modified gamma distribution is the normalized gamma with three free parameters (Petty and Huang 2011). The normalized gamma distribution accounts for varying LWC (Willis 1984) and is described by the intercept parameter $N_{w}$ $\left(\mathrm{m}^{-3} \mathrm{~mm}^{-1}\right.$; we will use $\log N_{w}$ for ease), median drop diameter $D_{0}(\mathrm{~mm})$, and shape parameter $\mu$ :

$$
N(D)=N_{w} f(\mu)\left(\frac{D}{D_{m}}\right)^{\mu} \exp \left[-(4+\mu) \frac{D}{D_{m}}\right],
$$

where $N_{w}\left(\mathrm{~mm}^{-1} \mathrm{~m}^{-3}\right)$ is defined as

$$
N_{w}=\frac{3.67^{4} 10^{3} \mathrm{LWC}}{\pi \rho_{w} D_{0}^{4}} .
$$

Additionally, $D_{m}$ is related to the median drop diameter through $\mu$ :

$$
D_{m}=\frac{4+\mu}{3.67+\mu} D_{0}
$$

Although the assumption of a normalized gamma fit to the DSD may not fully capture the true spectrum of rain DSDs (Thurai et al. 2017), we employ it here to place our results in context with the wide body of previous literature that invoked this assumption.

Further details of the gamma distribution can be found in Bringi and Chandrasekar (2001). To derive the parameters of the normalized gamma DSD from each minute of disdrometer data, the Thurai et al. (2014) methodology was adopted, which fits the gamma parameters through a $\mu$-search technique. For further information about DSD formulations and processing, see Bringi and Chandrasekar (2001), Thurai et al. (2014), and T15. Data were restricted to $\mu$ values in the range from -4 to 15 to ensure the gamma fit is a reasonable assumption. This screening process removed $<1 \%$ of data points in our dataset.

Several datasets included times when frozen precipitation was present (e.g., LPVEx, OLYMPEX, SGP, and Finland). For the shorter GV field projects with multiple 2DVDs, instruments and dates were excluded from analysis when snow contamination was identified (LPVEx and OLYMPEX; A. Tokay and J. Zagrodnik 2016, personal communication). However, for the longer datasets (SGP and Finland), a more automated method was developed to discard snow-contaminated observations. A distinct population of data exhibited lower-than-expected $R$ for a given LWC. Since $R$ is fundamentally related to the fall speed and size of each drop, this indicates a population of particles with fall speeds lower than that of rain (e.g., snow; Yuter et al. 2006). Thus, any days that had 10 or more points that fell below $R=9.0 \mathrm{LWC}^{1.1}$ (determined subjectively based on the anomalous population and examination of those days against ASOS observations of snow) were excluded from the analysis to remove snow contamination.

\section{b. $P C A$}

PCA is a technique often used in atmospheric science to simplify the analysis of large and complex datasets. In 
essence, PCA uses linear regression to explain the main modes of variability of a dataset. Hence, the variability of a dataset is distilled into its most important components. PCA can be thought of as a type of pattern or cluster analysis that explains the covariance of parameters simultaneously. Additionally, PCA is empirical in that the results are based solely on the dataset. For example, in the BR03 study, convective and stratiform DSD were stratified based on rain rate. In PCA, such assumptions are unnecessary.

PCA results in a set of vectors [also called empirical orthogonal functions (EOFs)] forming an orthogonal set of basis vectors and are ordered by their ability to explain the variability in the dataset. The first EOF is the vector that explains the largest amount of variance. The second EOF is orthogonal to the first EOF and describes the largest fraction of the remaining variance after the variance from the first vector has been removed. This process continues until the collective EOFs explain all of the variance (including noise). For example, if there are six input parameters, there will be six resulting EOFs, which will collectively explain $100 \%$ of the variance in the sample dataset. In practice, some studies may concentrate on the first few leading EOFs, since successive EOFs may yield little additional physical interpretation. For these reasons, we only present the leading two EOFs for our analysis. A linear combination of the EOF vectors describes each point in the dataset, the coefficients of which are known as the principal components (PCs). The PCs can be thought of as a measure of the resemblance between a particular data point and an EOF vector.

To prepare the disdrometer data for PCA, we constructed $M$ (number of attributes or quantities describing the DSD) arrays of length $N$ (corresponding to the number of DSD data points). For the PCA analysis, we selected $D_{m}, N_{w}$, and $\sigma_{m}$ to describe the DSD and the integral rain parameters $R$, LWC, and total number of drops $N_{t}$ to describe the DSD variability. These parameters are selected because they are commonly used to describe precipitation, they can be easily calculated from disdrometer measurements, and they provide meaningful information toward understanding the physics of rainfall. We have chosen to use the mass spectrum width $\sigma_{m}$ and the mean mass diameter $D_{m}$ instead of the gamma shape parameter $\mu$ and the median drop diameter $D_{0}$ because the former two variables can be calculated from the disdrometer measurements without the need to assume a gamma distribution. We use $N_{w}$ because it provides information about how the LWC is distributed across diameter space [Eq. (3)]. The covariance matrix among the six parameters for each latitude band and the global dataset are available in the online supplemental material (Fig. S1). The parameters of $N_{w}, N_{t}, R$, and LWC are lognormally distributed (e.g., Bringi and Chandrasekar 2001; T15) and are therefore included in the PCA in $\log$ form $\left(\log N_{w}, \log N_{t}, \log R\right.$, and $\log$ LWC). The data are normalized to standard anomalies of each characteristic quantity by subtracting the mean and dividing by the standard deviation. This was done to prevent quantities with large variances from dominating the EOFs, which could obscure scientifically relevant results. Additionally, deviations from the mean indicate when values are anomalously high or low, making simultaneous interpretation of multiple quantities easier. Once each quantity is standardized, the arrays are combined into a matrix of $N$ rows $\times M$ columns. The PCA returns $M$ orthogonal EOF vectors, with corresponding values of fractional variance explained, as well as $N$ PC values (corresponding to each data point) for each EOF vector.

The orthogonality constraint imposed by PCA can cause problems in certain situations. First, information about a particular process may be included in multiple EOFs because physical processes are not necessarily orthogonal. Second, each PC series can have positive and negative values. Since the sign of each EOF is arbitrary, each mode of variability has exactly two opposite components. This can complicate the physical interpretation of PCA results since physical processes are not always linear and orthogonal. Nonetheless, PCA provides an objective lens through which we can look at a large disdrometer dataset to gain novel insights about precipitation formation processes.

\section{Results}

\section{a. Comparisons of datasets}

We begin by examining the variability of DSDs across latitude bands projected in $\log N_{w}-D_{0}$ space (Figs. 2a-c). The BR09 and T15 C-S separation lines are included for context. In all locations, the most frequent values are centered near $D_{0}=1 \mathrm{~mm}$, with the median $\log N_{w}$ higher in the high latitudes (3.8-4) and lower in the midlatitudes (3-3.5). The midlatitudes have broader ranges of $D_{0}$ and $N_{w}$ compared to high and low latitudes. The characteristic bimodality in the tropics of $\log N_{w}$ is evident, which was noted by previous studies. The tropical distribution of $\log N_{w}$ peaks in terms of frequency of occurrence at 3.4 and also at 4 , and these maxima correspond to convective and stratiform populations (Ulbrich and Atlas 2007; BR09; Thurai et al. 2010; Bringi et al. 2012; T15). Indeed, this distinction serves as the basis for the T15 C-S separation line. We find it curious that the tropical datasets exhibit such a distinct bimodality in $\log N_{w}$ and $D_{0}$ associated with C-S rain. 

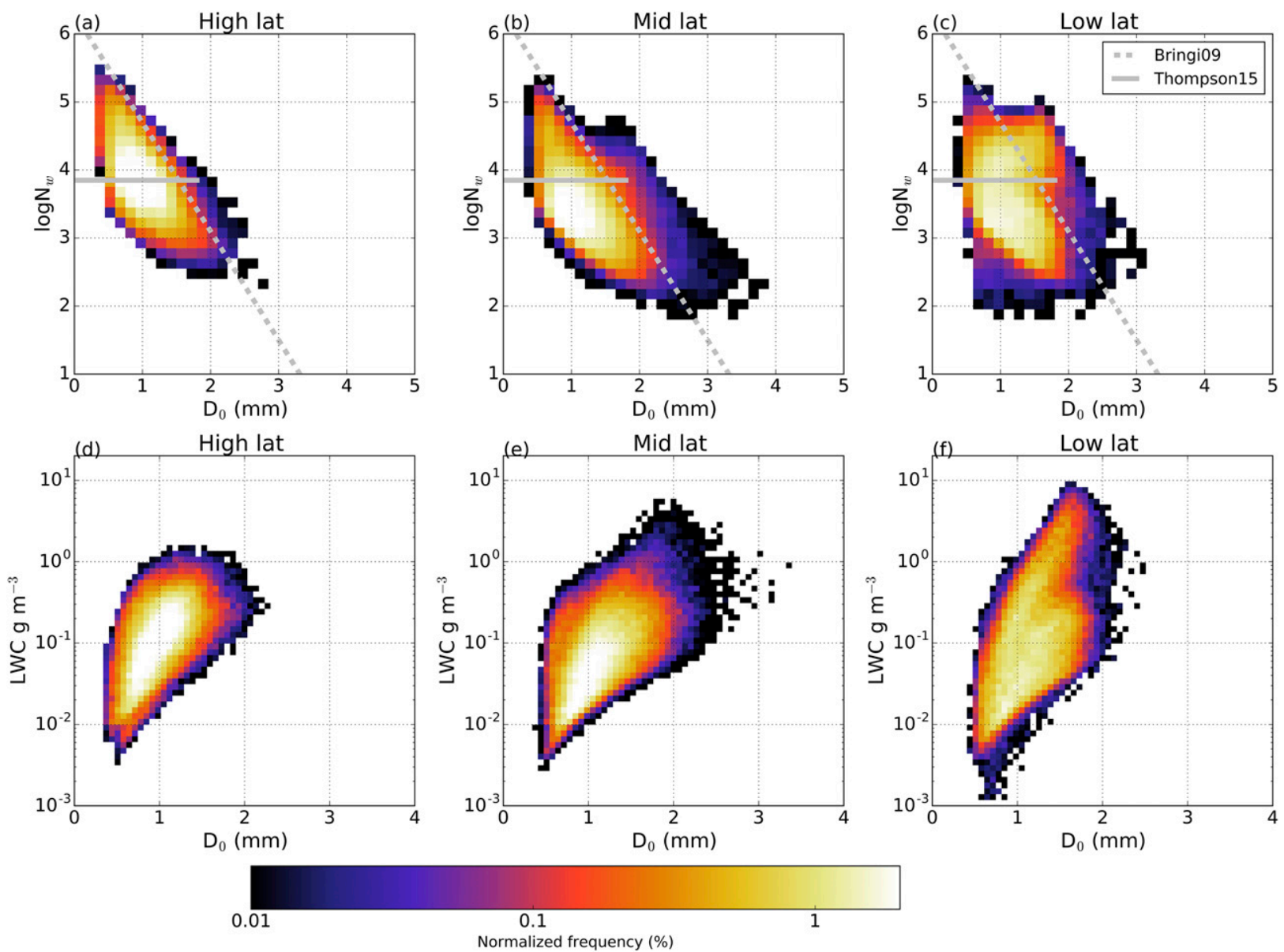

FIG. 2. Two-dimensional normalized frequency of occurrence as a function of latitude band for (a)-(c) $\log N_{w}-D_{0}$ and (d)-(f) LWC- $D_{0}$. The BR09 and T15 C-S lines are presented with gray dashed and solid lines, respectively, in (a)-(c).

This bimodality is lacking in other datasets such as the midlatitudes despite significant convective and stratiform precipitation components. In fact, the T15 line appears to cut through the mode of the $\log N_{w}-D_{0}$ distribution in the high latitudes, suggesting this method is only appropriate for characterizing C-S precipitation within the tropical oceans. It is possible that the intense ice-based precipitation in the midlatitudes somehow disrupts the clear separation seen in the tropics, where ice processes are likely weaker or play a lesser role in overall precipitation. Thus, the oceanic convection is size limited (e.g., constrained $D_{0}$ ) but dependent on LWC, which directly drives $\log N_{w}$ [Eq. (3)]. Another striking feature of the tropics is the moderate density of points clustered around $D_{0}=1.5 \mathrm{~mm}$ and $\log N_{w}=4-5$, a population that is not readily evident in the other locations. This is associated with a peak in $\mathrm{LWC}>1 \mathrm{~g} \mathrm{~m}^{-3}$ at about $D_{0}=1.7$ (Fig. 2f). Again, the tropics have two distinct clusters in $D_{0}-$ LWC space that have been noted in many previous studies (Tokay and Short 1996; Yuter and Houze 1997; T15) as being associated with convective (upper branch) and stratiform (lower branch) precipitation. The midlatitude datasets have a noticeable extension of large mean diameters for moderate LWC (Fig. 2e). The high latitudes rarely exceed $1 \mathrm{~g} \mathrm{~m}^{-3}$, with the most frequent values being $0.1-0.5 \mathrm{~g} \mathrm{~m}^{-3}$ (Fig. $2 \mathrm{~d}$ ). Interestingly, these median values are higher than the most frequent values in the other locations (Figs. 2d-f), which could be due to the atmospheric rivers affecting the OLYMPEX region (which dominate the highlatitude sample) bringing ample moisture to the domain (Houze et al. 2017).

It is obvious from Fig. 2 that DSDs vary by location (individual locations shown in Figs. S2 and S3), and as in the case of C-S separation lines, there may be important underlying microphysical processes that are responsible for this variance. It is also clear that no one location fully captures the entire spectrum of global DSD variability. Given this regional DSD variability, we are motivated to ask, what are the primary modes of temporal and spatial 

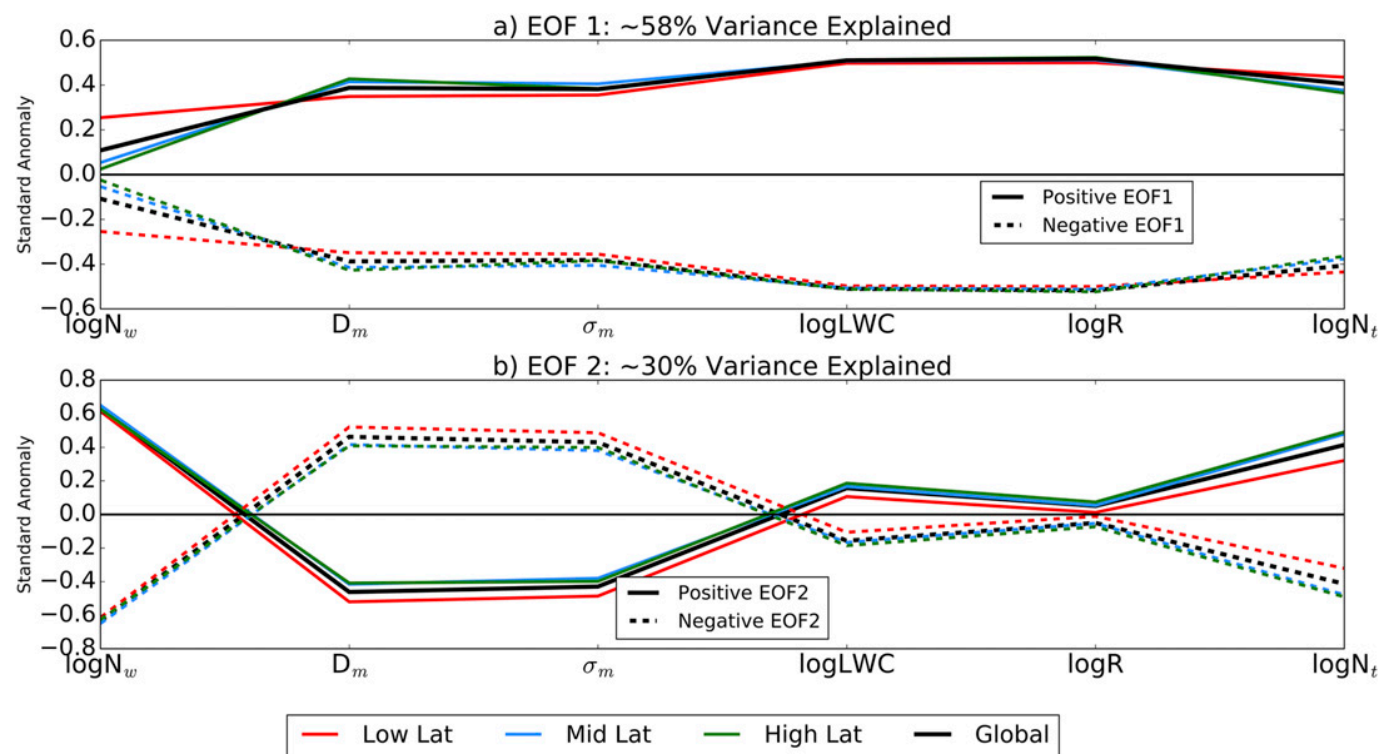

FIG. 3. The first two EOFs for each latitude band and the global dataset (black). Solid lines indicate the positive modes, and dashed lines indicate the negative modes (where the sign is arbitrary).

DSD variability across the globe? Can different surface DSDs be explained and linked to the microphysical processes shaping them aloft? We explore these questions next.

\section{b. PCA results}

Figure 3 shows the first two primary EOFs associated with the DSD characteristic parameters $\left(\log N_{w}, D_{m}, \sigma_{m}\right.$, $\log \mathrm{LWC}, \log R$, and $\log N_{t}$ ). The standard anomaly associated with each parameter for each of the resulting EOFs is indicated. Importantly, despite some spread in the magnitude of the standard anomalies, every location shows the same modes of covariance in the first two EOFs. Although we present the aggregate of datasets in a given latitude band, this finding holds true for every individual dataset (Fig. S4). Again, we note that the sign of each PC is arbitrary and that mathematically the positive and negative modes are exact opposites. We have neglected the EOFs beyond EOF2, which collectively explain a much smaller amount of variability and may relate to measurement noise or higher-order temporal variability rather than underlying physical processes (Larsen and O'Dell 2016). It is important to note that the first two EOFs explain $\sim 88 \%$ of the variability across all latitude bands (Table 2). The positive mode of EOF1 is associated with relatively high $\log \mathrm{LWC}$ and $\log R$, large $\log N_{w}$, large $D_{0}$, and high $\sigma_{m}$. This EOF explains $57 \%-62 \%$ of the variability in each location and $58 \%$ globally (Table 2). EOF2, which explains $20 \%-31 \%$ of the variability ( $30 \%$ globally), is characterized by relatively $\operatorname{large} \log N_{t}$ and $\log N_{w}$ and small
$D_{0}$ and $\sigma_{m}$ in the positive mode but relatively little variability in $\log \mathrm{LWC}$ or $\log R$.

To equally compare resulting EOFs from different locations, each of which may or may not capture the full breadth of DSD variability, we normalize all data against the global dataset (i.e., all data combined) by subtracting the global mean and dividing by the standard deviation. All subsequent results are shown relative to this global normalization and global EOFs.

It is most useful to examine these orthogonal modes of variability by investigating data points that are most characteristic of each mode. This is accomplished by isolating points with the largest PC values, which represent where the points project most strongly onto an EOF. To this end, unless otherwise indicated, we select a threshold of $|1.5|\left(\sigma_{1.5}\right)$ for all PCs. The selection of points that do not meet these criteria will be referred to as "ambiguous" because they bear resemblance to multiple EOFs. Here, we note that these threshold values are somewhat arbitrary and the high thresholds used herein have been selected to highlight differences between populations, but the overall results do not change with the prescribed threshold; larger values result in more distinct separation between opposing modes, while smaller values result in more overlap.

The distributions of $\mathrm{PC} 1$ and $\mathrm{PC} 2$ for each latitude band are shown in Fig. 4. The $\sigma_{1.5}$ thresholds are illustrated with dashed lines. While the bulk of points $(\sim 77 \%)$ are contained below the thresholds (by design), $23 \%$ of points meet one or more of these thresholds; in fact, there is a noticeable population with large absolute 
TABLE 2. Percent variance explained by the first two EOFs.

\begin{tabular}{lccc}
\hline \hline Experiment & EOF1 & EOF2 & Total \\
\hline Global & 58 & 30 & 88 \\
High latitude & 57 & 31 & 88 \\
Midlatitude & 59 & 20 & 89 \\
Low latitude & 62 & 26 & 88 \\
\hline
\end{tabular}

PC1 and PC2 values. Leveraging these PC distributions, we define six distinct groups. Illustrated by colored boxes in Fig. 4, these groups are positive PC1 but ambiguous PC2 (group 1; red), negative PC1 (group 2; green), positive $\mathrm{PC} 2$ but ambiguous $\mathrm{PC} 1$ (group 3; yellow), negative $\mathrm{PC} 2$ and ambiguous $\mathrm{PC} 1$ (group 4; blue), positive PC1 and positive PC2 (group 5; orange), and positive PC1 and negative $\mathrm{PC} 2$ (group 6; purple).

Already, clear latitudinal differences emerge from this PC-based grouping (Fig. 4). For example, the high latitudes have a large number of points in group 3 but few points in group 5, group 1 , or group 6 at the $\sigma_{1.5}$ threshold. In contrast, the low latitudes have a number of points in both group 1 and group 5. The midlatitudes have the largest number of points in group 6 of any latitude band. The relative percentages of each group in each band is shown in the supplemental material (Fig. S5). We will probe the characteristics of each of these six populations in the next section to understand their potential origins from a microphysical perspective and possible implications.

\section{c. DSD parameters}

Here, we will cast the results of the PCA into different formulations and 2D distributions for physical interpretation and comparison with previous studies. For example, BR09 and T15 found distinct populations in $\log N_{w}-D_{0}$ and LWC $-D_{0}$ space, which they attributed to convective and stratiform rainfall.

Mean gamma DSD, determined by inserting the mean values for $N_{w}, D_{0}$, and $\mu$ into Eq. (2) for each of the six groups identified above, contrasts the characteristic size distributions associated with the associated covariance among the DSD parameters (Fig. 5a). Figure 5b illustrates the normalized (section $2 b$ ) mean values of the different parameters for each of the six groups. For reference, the global mean values of LWC, $R, N_{t}, \sigma_{m}$, and the gamma parameters $\left(\log N_{w}, D_{0}\right.$, and $\left.\mu\right)$ are annotated in Fig. 5a, and mean values of the gamma parameters are listed in Tables 3-5. Group 1 (red) is associated with $R$ significantly larger than $4 \mathrm{~mm} \mathrm{~h}^{-1}$ (the global mean), shape parameters $\mu<4$, and mean drop diameters $D_{0}>1.1 \mathrm{~mm}$, resulting in a broad size distribution. In contrast, group 2 (green) is characterized by narrow size distributions (Fig. 5a) and relatively low $R$ and LWC (Fig. 5b). Both groups 4 (blue) and 6 (purple) have strong negative anomalies in $\mu$ (i.e., smaller than the global mean of 4), resulting in more exponentialtype (broad) size distributions (Fig. 5a). While having anomalously large $D_{0}$ and $\operatorname{low} \log N_{w}$, group 6 also has anomalously high $\log R, \log \mathrm{LWC}$, and drop concentrations $\left(\log N_{t}\right)$. Here, we recall that $N_{w}$ is directly proportional to LWC but inversely proportional to $D_{0}^{4}[\mathrm{Eq}$. (3)]. The resulting anomalously $\operatorname{low} \log N_{w}$ is due to the exceptionally high $D_{0}$ anomalies even though the total number of drops and LWC are high. Group 3 has a high $\log N_{w}$ consistent with the smallest mean mass-weighted diameter, indicating a population of numerous small drops with little size dispersion. This population also has $\log L W C$ and $\log R$ values near the global mean. However, DSDs in group 5 (orange) have the highest anomalies of $\log R$ and $\log \mathrm{LWC}$, greatest total number of drops, and highest $\log N_{w}$.

These PCA-guided groups result in distinct clusters in 2D parameter space (Figs. 6 and 7). Again, we note that although we only display the aggregate results for the three latitude bands, these clusters are repeatable in every dataset considered (see Fig. S6). Perhaps most striking, but maybe not unexpected because of the orthogonality of the EOF analysis, is the distinction in $\log N_{w}-D_{0}$ space (Figs. 6a-c). Group 1 (red) resides in the moderate to high $D_{0}$ and moderate to $\operatorname{low} \log N_{w}$, but it is clear this group contains the highest LWC observations in our dataset, along with group 5 (Figs. 7a-c). This population of points is associated with relatively low, even negative, values of $\mu$ (Figs. 6d-i), indicating broad size distributions (Fig. 5a). The surprising conformity of this cluster in the tropics to the robust C-S lines proposed by T15 and BR09 underpins group 1 as convective. Conversely, the points in group 2 (green) are confined to relatively small $D_{0}$ values and $\operatorname{low} \log N_{w}$ because of the combined effect of low LWC and small $D_{0}$. The bulk of the population falls in the stratiform classification for both BR09 and T15 C-S in the tropics. Additionally, this cluster has generally high $\mu$ values $(>6)$, indicating relatively narrow size distributions (Figs. 6d-f and 5a) or perhaps that a normalized gamma distribution is inadequate to describe the distribution of these particular samples (Thurai et al. 2017).

Group 3 (yellow) points are largely restricted to $\log N_{w}$ values larger than 4.5 because of a wide range of LWC but small $D_{0}$ (Figs. 7a-c), with the bulk of the population having small $(<\sim 1.0 \mathrm{~mm}) D_{0}$ (Table 3$)$. Group 3 points span nearly all $\mu$ (Figs. $6 \mathrm{~d}-\mathrm{i}$ and $7 \mathrm{~g}-\mathrm{i}$ ), especially in the high latitudes, but the majority are larger than $\mu=5$ (Table 5). The group 3 population falls in the region of the spectrum that both BR09 and T15 attribute to weak, shallow radar echoes. Group 4 (blue) is associated with 

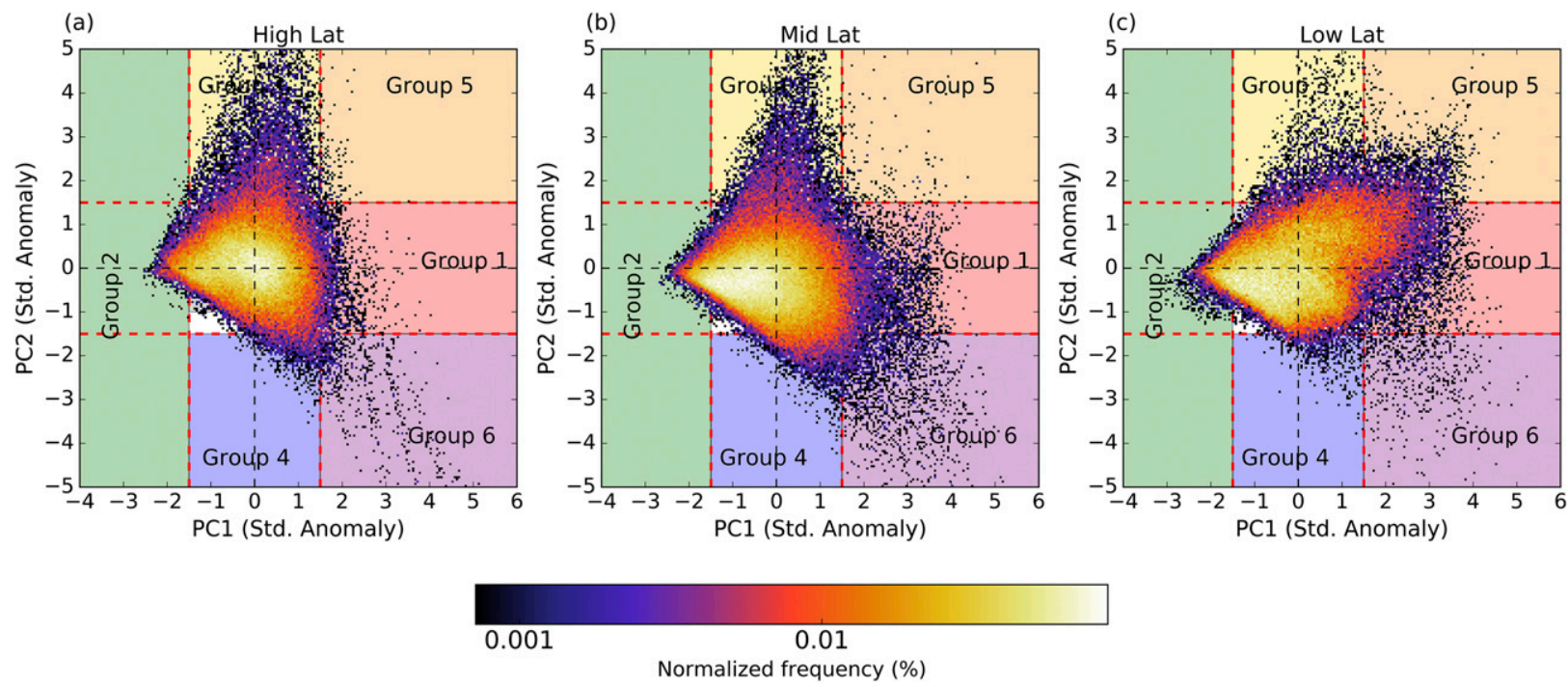

FIG. 4. Frequency density of joint distributions of PC1 and PC2. Dashed red lines illustrate the $\sigma_{1.5}$ thresholds, and the dashed black lines indicate the 0 value for PC1 and PC2. Shaded boxes represent the six groups of points with similar characteristics based on PCA.

large $D_{0}(>1.5 \mathrm{~mm}$, up to $3 \mathrm{~mm})$ and $\operatorname{low} \log N_{w}(<3.5$, as low as 1$)$, which is a function of both the large sizes and the relatively low LWC (Fig. 7). Group 4 has $\mu$ values generally $<3$, centered from around -1 to 0 (Figs. $6 \mathrm{~d}-\mathrm{f}$; Tables 3-5).
The two groups with large absolute values of PC1 and PC2 (groups 5 and 6; orange and purple, respectively) have notable properties. Group 5 is more common in the tropics compared to the midlatitudes and high latitudes. Group 5 is characterized by the largest total number of
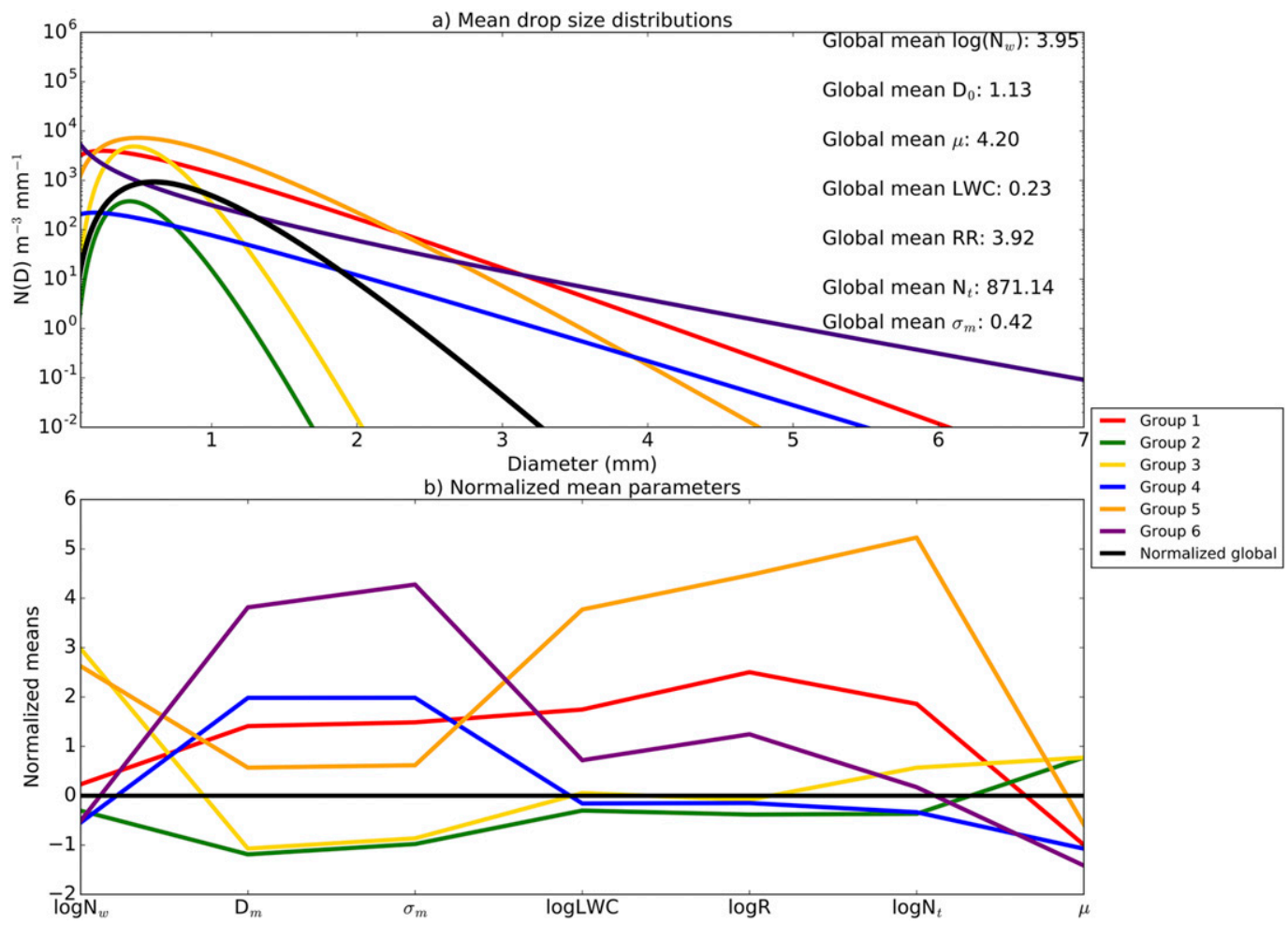

FIG. 5. (a) Global characteristic size distributions using the mean values for each identified group. Global means of all data points are indicated. (b) Normalized mean values of parameters for the six groups. 
TABLE 3. Mean $D_{0}$ values for the six groups using the PC thresholds in Fig. 4.

\begin{tabular}{llcccccc}
\hline \hline Experiment & All & Group 1 & Group 2 & Group 3 & Group 4 & Group 5 & Group 6 \\
\hline Global & 1.13 & 1.79 & 0.67 & 0.81 & 2.16 & 1.35 \\
High & 1.0 & 1.71 & 0.59 & 0.68 & 1.93 & 0.98 \\
Mid & 1.18 & 2.05 & 0.68 & 0.70 & 2.21 & 2.62 \\
Low & 1.18 & 1.62 & 0.70 & 1.07 & 2.24 & 1.23 \\
\hline
\end{tabular}

drops and the largest LWC despite $D_{0}$ near the global mean of $1.13 \mathrm{~mm}$. These points are exclusively above the BR09 and the T15 convective lines in the tropics. In contrast, the midlatitudes have the most points in group 6 , which consist of relatively high LWC and moderate $N_{t}$ but very large sizes, leading to $\operatorname{low} \log N_{w}$ values (Fig. 6b). This group also has the lowest $\mu$ because of the large number of drops and large mean $D_{0}$.

\section{d. Radar observations}

We have demonstrated a distinct clustering of surface DSD parameters and speculated about possible physical processes producing these distributions. To further investigate the possible microphysical processes contributing to the DSDs in each of the six groups, we examined the vertical structure of radar echoes over specific disdrometer locations using polarimetric radar observations. In each case, range-height indicator (RHI) and/or plan position indicator (PPI) scans were used to geolocate the radar gates above the disdrometer locations, creating a vertical profile over the disdrometer. These vertical profiles were then time matched to the disdrometer PCA group classifications. This analysis provides an independent method to study the characteristics of each group because the radar and the disdrometer are separate measurements.

Mean reflectivity $Z$ and differential reflectivity $Z_{\mathrm{dr}}$ profiles were created from RHI data for each disdrometer PCA group (Fig. 8). It should be noted that for the radar analysis in this section, the PC thresholds have been lowered for illustration purposes. That is, the matched radar-disdrometer times may not have many points that meet the $\sigma_{1.5}$ thresholds, since only $22 \%$ of points in the entire disdrometer database meet these thresholds. To make this problem tractable, we will focus on specific locations: OLYMPEX to represent the high latitudes; MC3E, IFloodS, and IPHEx for the midlatitudes; and Gan Island and Darwin for the tropics, all providing coincident polarimetric data over nearby disdrometers (Table 6). The disdrometer PC values spanning five minutes around the radar RHI time were averaged and used to assign the radar profiles to a particular group. Six RHI gates over each point are averaged, and RHI gate heights were interpolated to a common set of heights for comparison. To account for clutter at the lowest radar bins, the heights start at $0.2 \mathrm{~km}$ AGL. The analysis resulted in 1466 (midlatitude), 1336 (low latitude), and 3320 (high latitude) disdrometer/radar matches with precipitation (Table 6). Mean $Z$ and $Z_{\mathrm{dr}}$ for each match were smoothed with a Gaussian filter in height. In each profile, the $0-\mathrm{dB} Z$ echo-top height (ETH) was calculated and plotted against the reflectivity at $2.5 \mathrm{~km}$ (Figs. $8 \mathrm{~g}-\mathrm{i}$ ) as an estimate of the mean intensity and depth of precipitation in each group. We recognize the complexities of linking vertical information to surface observations because of advection and point-to-volume comparisons, and these effects may dilute the signal in the analysis below. However, we have attempted to minimize these effects through spatial and temporal averaging of the radar and disdrometer data.

Although the systematic increase in ETH with decreasing latitude is evident (perhaps due to the annual mean tropopause height; Price and Rind 1993), there are clear trends within each group across latitudes (Fig. 8). Groups 1 and 6 have the highest mean reflectivity values (for all latitudes) throughout the depth of the column and significant ETH. Groups 2 and 3 have the lowest mean reflectivities and lowest ETH. Mean ETH in group 3 remains below $5 \mathrm{~km}$ in the high and midlatitudes, and mean reflectivities are below $20 \mathrm{~dB} Z$ in all latitude bands, suggesting a designation of shallow, weak warm rain showers for this group. Group 2 has similar mean $Z$ and ETH values to group 3 and a relative

TABLE 4. Mean $\log N_{w}$ values for the six groups using the PC thresholds in Fig. 4.

\begin{tabular}{lccccccc}
\hline \hline Experiment & All & Group 1 & Group 2 & Group 3 & Group 4 & Group 5 & Group 6 \\
\hline Global & 3.95 & 4.19 & 3.64 & 4.73 & 2.87 & 4.69 & 3.04 \\
High & 4.12 & 4.14 & 3.93 & 4.81 & 3.08 & 4.94 \\
Mid & 3.79 & 3.85 & 3.53 & 4.71 & 2.78 & 4.80 & 2.96 \\
Low & 3.94 & 4.34 & 3.46 & 4.63 & 2.82 & 4.66 \\
\hline
\end{tabular}


TABLE 5. Mean $\mu$ values for the six groups using the PC thresholds in Fig. 4.

\begin{tabular}{lccccccc}
\hline \hline Experiment & All & Group 1 & Group 2 & Group 3 & Group 4 & Group 5 & Group 6 \\
\hline Global & 4.20 & 0.64 & 6.91 & 6.23 & -0.02 & 2.14 & -0.79 \\
High & 4.44 & 0.23 & 6.82 & 6.75 & -0.51 & 2.36 & -1.07 \\
Mid & 4.35 & 0.30 & 7.26 & 7.18 & 0.20 & 2.70 & -0.61 \\
Low & 3.70 & 0.99 & 6.48 & 4.61 & -0.36 & 2.08 & -1.20 \\
\hline
\end{tabular}

maximum in $Z_{\mathrm{dr}}$ near the environmental freezing level (e.g., the radar brightband signature). We suggest that this group is likely associated with weak vertical motions indicative of stratiform precipitation, where particles grow by vapor deposition and aggregation and then melt as they fall below the $0^{\circ} \mathrm{C}$ level (Houze 1997) or are detrained from deep convection and continue to grow in mesoscale updrafts as they fall out (Rutledge and Houze 1987). These processes fundamentally limit the maximum drop diameters and rain rates (Yuter and Houze 2002). Group 4 has a very distinct signature, especially in the midlatitude samples. Group 4 has high ETH and modest peak reflectivities $(<30 \mathrm{dBZ})$. At subfreezing temperatures, radar reflectivities increase toward the melting layer while $Z_{\mathrm{dr}}$ is slightly positive aloft and then decrease toward the melting layer, reaching a minimum near $0 \mathrm{~dB}$ just above the environmental melting layer. While this behavior is evident in all midlatitude $Z_{\mathrm{dr}}$ profiles, it is most notable in group 4 . This is consistent with small-oriented ice crystals aloft (Kennedy and Rutledge 2011; evident by weak reflectivity and positive $Z_{\mathrm{dr}}$ ) that begin to aggregate to form larger particles that increase reflectivity and decrease $Z_{\mathrm{dr}}$ to near zero (associated with very low bulk density and small degrees of oblateness). However, once these particles begin to melt, they produce a sharp increase in both reflectivity and $Z_{\mathrm{dr}}$ (e.g., the radar brightband signature). We postulate that group 4 is consistent with depositionaggregation-driven stratiform precipitation. There were too few coincident RHIs in group 5 in the midlatitude samples $(<20)$, so they are not shown. At Gan Island (OLYMPEX), the mean ETH for group 5 reaches $8(5) \mathrm{km}$ compared to the deeper groups 1 and 6 , at $\sim 9(6) \mathrm{km}$. In both locations, $Z$ values are larger than group 2 or group 3 , particularly below the melting layer. In the low latitudes, $Z_{\mathrm{dr}}$ remains constant or increases slightly below the melting layer while $Z$ increases, which is a signature of robust collision-coalescence in the warm layer (Kumjian and Prat 2014). The group 5 signature in OLYMPEX is associated with decreasing $Z_{\mathrm{dr}}$ in the shallow warm layer. This signature has been attributed to drop breakup (Kumjian and Prat 2014); however, this mechanism is unlikely in the OLYMPEX regime because of the short fall distance of drops and generally small drop sizes. Therefore, the physical processes underpinning group 5 in the high latitudes is unclear. The $Z_{\mathrm{dr}}$ profiles of group 6 exhibit increases below the melting layer, especially in the midlatitudes, which had the largest number of samples in this group. The high ETH and large reflectivities above the melting layer are consistent with strong convective vertical motions and are similar to the median convective vertical profiles of midlatitude convection illustrated in Carr et al. (2017). The larger $Z$ throughout the column and warm-layer $Z_{\mathrm{dr}}$ values of group 6 are consistent with a signature of ice-based convection and melting below the $0^{\circ} \mathrm{C}$ layer. The increasing $Z_{\mathrm{dr}}$ and $Z$ toward the surface suggest continued coalescence growth below the melting layer (Kumjian and Prat 2014).

To put these mean samples into a larger spatial context, we examined time-height series for several cases in each latitude band. The AMIE Gan and OLYMPEX experiments both employed high-temporal-resolution RHI scanning, so time-height series were created by averaging 30 gates in range at each disdrometer gate for each elevation over the disdrometer point. Time-height series for IFloodS and Darwin used PPI data by averaging 10 gates in the azimuthal direction and 30 gates in range over the disdrometer location for each elevation, similar to the quasi-vertical profile (QVP) method described by Ryzhkov et al. (2016) but averaged over a smaller area. Representative reflectivity time-height series for each latitude band for different groups are shown in Figs. 9-11.

An example from Darwin on 16 January illustrates a region of stratiform precipitation followed by a convective cell passing near the disdrometer at 1205 UTC (Fig. 9a). The majority of the time series is classified as group 4 by the disdrometer during clearly stratiform precipitation, evidenced by a persistent bright band around $5 \mathrm{~km}$. The passage of the convective core results in a brief classification of group 1. A second tropical example from Gan Island shows a widespread stratiform region with a continuous bright band evident at the environmental melting level $(\sim 5 \mathrm{~km})$. As an embedded convective element passes by around 0420-0450 UTC (Fig. 9e), reflectivities are enhanced below the bright band, and the group switches from 1 to 5 as PC2 values increase (Fig. 9g). After this time, the PCA is ambiguous before switching to group 6 as the heavy stratiform 

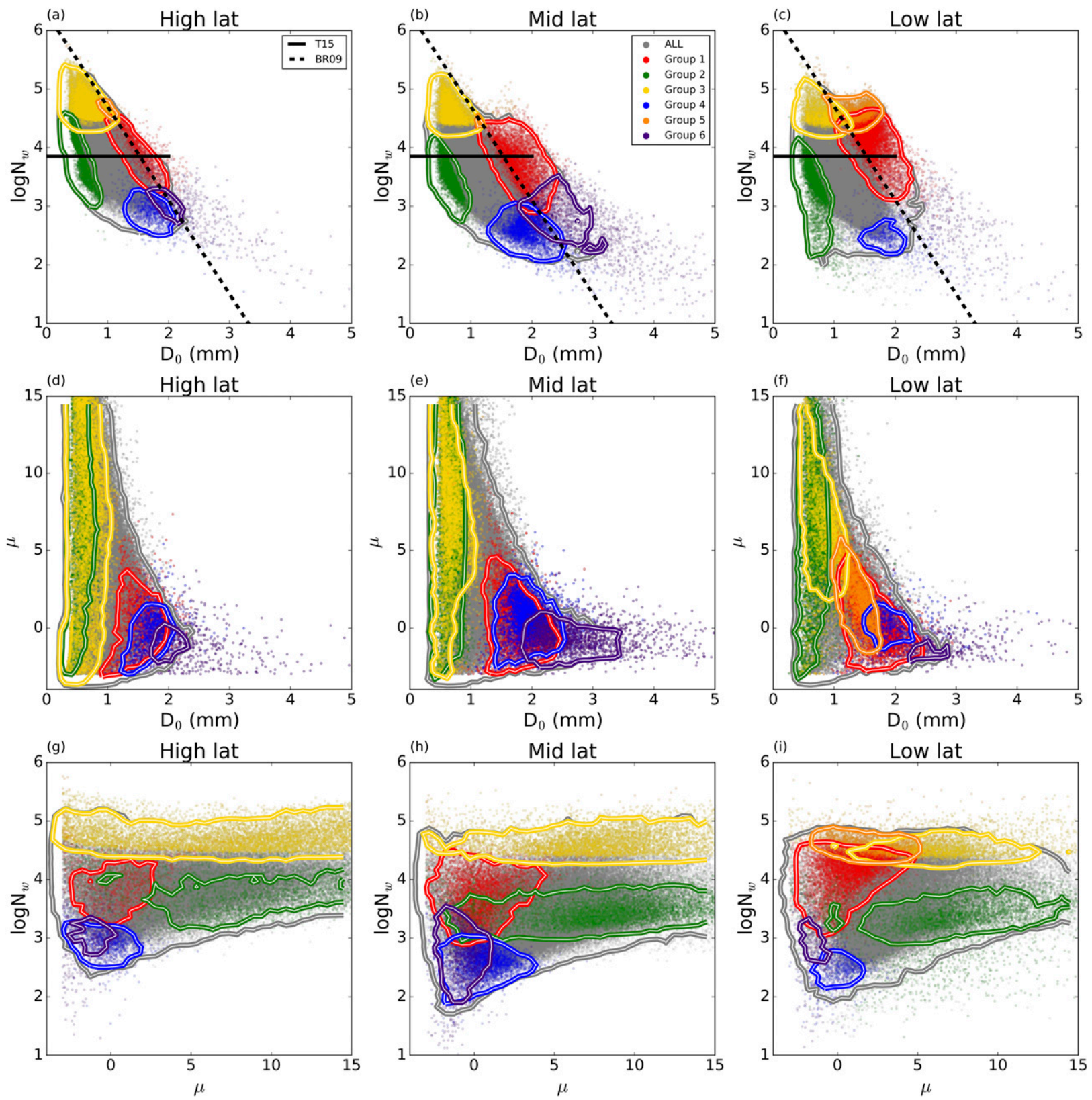

FIG. 6. Two-dimensional distributions of each group in the (left) high-, (center) mid-, and (right) $\operatorname{low}-\operatorname{latitude}$ bands for (a)-(c) $\log N_{w}-D_{0}$, (d)-(f) $\mu-D_{0}$, and (g)-(i) $\log N_{w}-\mu$ space. The gray dots encompass the entire space for each dataset and represent the points that did not meet PC thresholds (ambiguous); red is group 1, green is group 2, yellow is group 3, blue is group 4, orange is group 5, and purple is group 6. Contours highlight smoothed Gaussian 1- $\sigma$ points for each group. In (a)-(c), the solid black line is the T15 C-S separation line for the tropical oceans and the dashed black line is the BR09 C-S separation.

precipitation sets in (Fig. 9e) and finally groups 4 and 2 as the stratiform echo weakens. This example is also illustrated in T15 and shows the transition from convective (groups 1 and 5) to stratiform (groups 2 and 4) precipitation. The last tropical example, also from Gan Island, shows what is termed "weak, shallow convection" by T15. Reflectivities are largely below $25 \mathrm{dBZ}$, and the echo top remains below the melting layer in an area of weak echoes
(Fig. 9i). The disdrometer PCA shows small PC1 and positive PC2, mostly classified as groups 2 and 3 .

The first example from IFloodS, representing the midlatitudes, shows the passage of an intense deep convective core, with peak reflectivities $>50$ - and $40-\mathrm{dB} Z$ echoes reaching $10 \mathrm{~km}$, followed by a fledgling stratiform region (Fig. 10a). As the core passes over the disdrometer, large PC1 values result in a group 1 

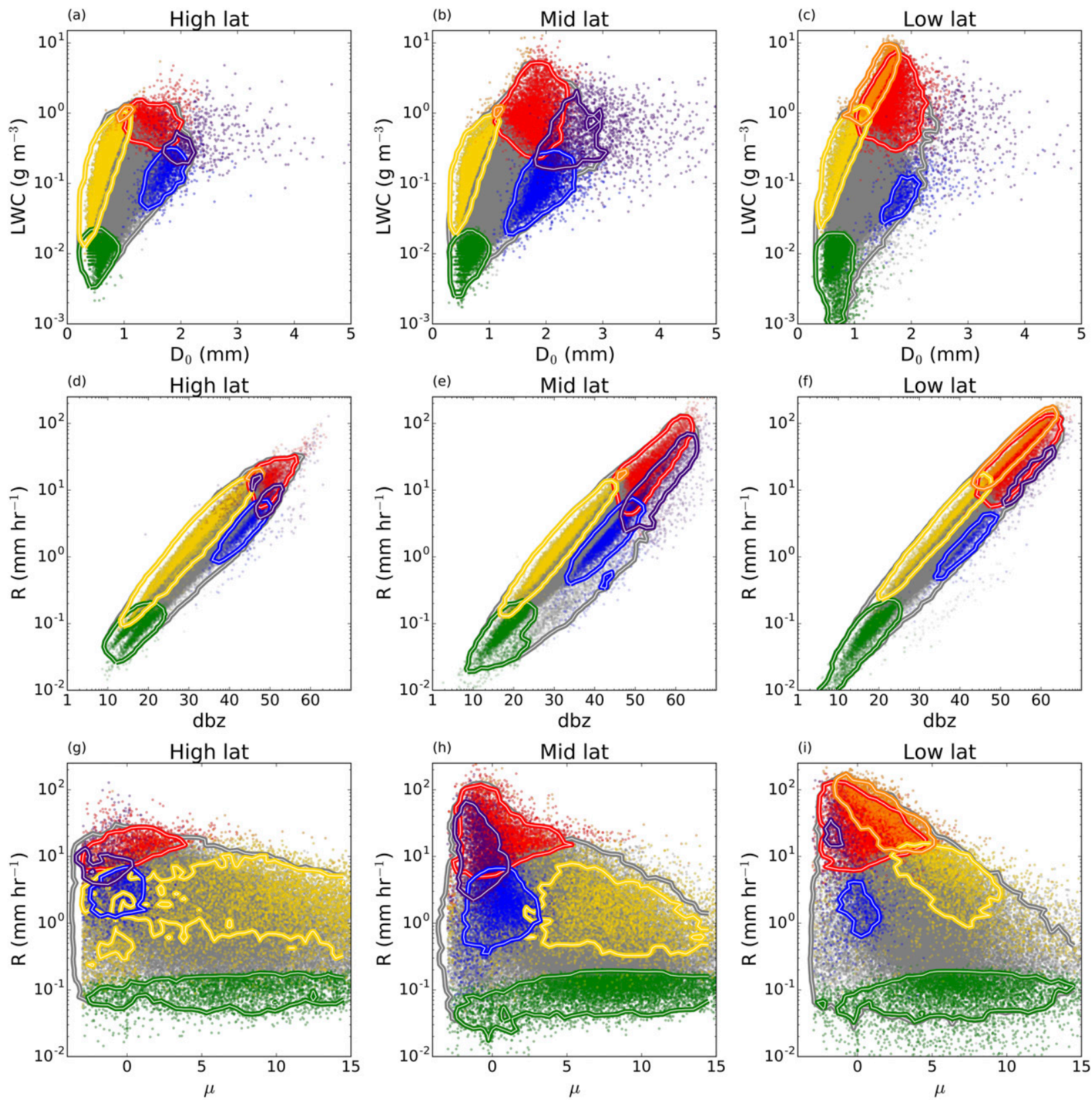

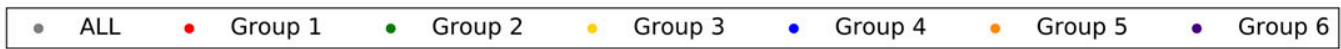

FIG. 7. As in Fig. 6, but for (a)-(c) LWC- $D_{0}$, (d)-(f) $Z-R$, and (g)-(i) $R-\mu$ space.

classification, followed by a narrow band of group 6 on the back edge of the core, then group 4 , and finally group 2 as the stratiform precipitation sets in after 1015 UTC. The second IFloodS example (Fig. 10e) shows a small, shallow convective cell passing around 1840 UTC, followed by a region of "lumpy stratiform" with a clear brightband signature but some enhanced reflectivity above the bright band between 1855 and 1955 UTC. The small convective cell with echo heights only reaching $6 \mathrm{~km}$ and reflectivities $\sim 35 \mathrm{dBZ}$ is associated with a limited number of group 5 identifications. Group 4 is identified where the bright band has strong reflectivities $(>30 \mathrm{~dB} Z)$, and the most intense bright band with reflectivities approaching $40 \mathrm{dBZ}$ is identified as group 6 and even some group 1. As the stratiform weakens after 1955 UTC, the disdrometer PCA identifies mostly group 2. The last example also illustrates a period of lumpy 

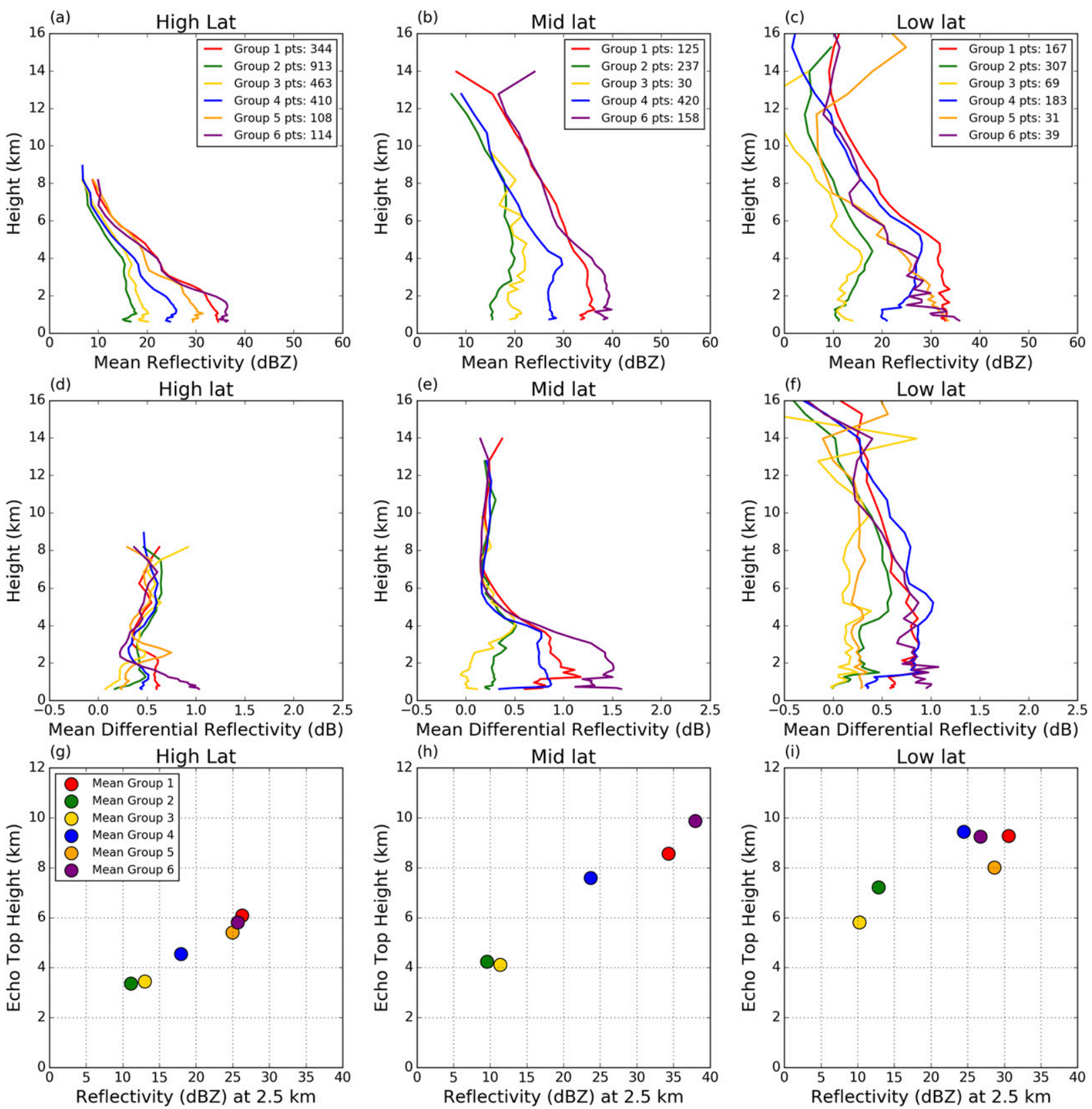

FIG. 8. Vertical structure of (a)-(c) reflectivity and (d)-(f) differential reflectivity $Z_{\mathrm{dr}}$ for each of the six groups from coincident radar RHIs for the (left) high-, (center) mid-, and (right) low-latitude bands. (g)-(i) The mean reflectivity at $2.5 \mathrm{~km}$ as a function of the mean radar 0-dBZ echo-top height as a function of group determined by the surface disdrometer. Here, the low latitudes are composed from Darwin and Gan Island data; the midlatitudes from IFloodS, MC3E, and IPHEx data; and the high latitudes from OLYMPEX radar data. Note that the numbers composing each group indicated in the legends of (a)-(c) do not match those given in Table 6 because of the ambiguous points, which are not shown. PC thresholds of $\sigma_{1.0}$ were used for this analysis.

stratiform, with a clear brightband signature but enhanced reflectivity aloft (Fig. 10i). Group 1 is identified early in the time period but switches to group 6 as $30-\mathrm{dB} Z$ reflectivities reach $6-8 \mathrm{~km}$ accompanied by large reflectivities in the bright band $(>45 \mathrm{dBZ})$. As the bright band and reflectivities aloft weaken, the classification switches to group 4 and some group 2 (both identifying stratiform precipitation).

The last examples illustrate the unique coastal mountain high-latitude regime in OLYMPEX. Groups 1 and 6 are identified during a period of strong low-level reflectivities, upward of $40 \mathrm{~dB} Z$ below $3 \mathrm{~km}$, the approximate height of the 
TABLE 6. Summary of the radar characteristics and disdrometer matches.

\begin{tabular}{|c|c|c|c|c|c|c|c|}
\hline Project & Radar & $\begin{array}{c}\text { RHI } \\
\text { elevations }\end{array}$ & $\begin{array}{c}\text { PPI elevations } \\
\text { (No., highest elevation) }\end{array}$ & $\begin{array}{l}\text { Resample } \\
\text { time }\end{array}$ & Disdrometer & $\begin{array}{l}\text { Distance to } \\
\text { disdrometer }\end{array}$ & $\begin{array}{l}\text { No. of } \\
\text { raining matches }\end{array}$ \\
\hline OLYMPEX & NPOL & $0^{\circ}-45^{\circ}$ & - & $20 \mathrm{~min}$ & APU03, APU05, APU08 & $19,32,40 \mathrm{~km}$ & 3320 \\
\hline IFloodS & NPOL & $0^{\circ}-20^{\circ}$ & $12,5^{\circ}-8^{\circ}$ & $2-5 \min$ & SN36, SN37 & $25,47 \mathrm{~km}$ & 1112 \\
\hline IPHEx & NPOL & $0^{\circ}-60^{\circ}$ & - & $2-5 \min$ & SN35, SN36 & $22,42 \mathrm{~km}$ & 354 \\
\hline MC3E & NPOL & $0^{\circ}-40^{\circ}$ & $28,35^{\circ}$ & $1-5 \min$ & SN25, SN70 & $33,28 \mathrm{~km}$ & 1919 \\
\hline Gan & SPOL & $0^{\circ}-60^{\circ}$ & - & $15 \mathrm{~min}$ & 2DVD & $8 \mathrm{~km}$ & 519 \\
\hline Darwin & CPOL & $0^{\circ}-45^{\circ}$ & $17,42^{\circ}$ & $10 \mathrm{~min}$ & JWD & $23 \mathrm{~km}$ & 817 \\
\hline
\end{tabular}

environmental melting layer during this time. In a 2-km-deep layer above the melting level, reflectivities are up to $35 \mathrm{dBZ}$, and echo tops are $\sim 8 \mathrm{~km}$ (Fig. 11a). A contrasting example (Fig. 11e) illustrating mostly group 6 and some group 4 shows shallower echo tops (around $6 \mathrm{~km}$ ) but similar strong reflectivities in the warm layer (below $2 \mathrm{~km}$ in this case) and some more intense periods with reflectivities above $45 \mathrm{dBZ}$ (e.g., 1145 UTC). These intense periods are classified as group 6. In contrast to the first OLYMPEX example, reflectivities fall off near the surface. As the reflectivity aloft weakens after 1250 UTC, groups 4 and 2 are evident. Finally, a period of weak, shallow reflectivity is illustrated by the example in Fig. 11i. Echo tops are lower in comparison to the previous two cases $(<4 \mathrm{~km})$, and reflectivities are limited to $<30 \mathrm{dBZ}$. The majority of these points are classified as group 3, similar to the weak, shallow echoes accompanying group 3 in the tropical example (Fig. 9g).

These specific examples serve to support our hypothesis that group 1 encompasses convection, with stronger reflectivities and deeper echoes (Figs. 9a,b, 10a, and 11a). The hypothesized stratiform nature of group 2 is also supported by these examples, as this group is generally identified by the disdrometer when radar echoes display a weak to moderate bright band and reflectivities remain below $30 \mathrm{dBZ}$ (Figs. 9a, 10e, and 11i). Radar examples support the hypothesis that group 3 is associated with weak, shallow echoes (Figs. 9i, 11i), while group 4 appears to be associated with more intense stratiform precipitation, where brightband reflectivities are $>35 \mathrm{dBZ}$ (Figs. 9a,e, 10e,i, and 11e). According to the radar analysis, group 5 appears when reflectivities in the warm layer are significant $(>30 \mathrm{~dB} Z)$, suggesting the presence of robust coalescence processes (Fig. 9e). Group 6 is generally associated with the most intense reflectivities, sometimes on the edge of a convective core (Fig. 10a), sometimes in strong, lumpy stratiform (Figs. 10e,i, and $11 \mathrm{a}, \mathrm{e})$, suggestive of larger melted ice particles.

\section{Discussion and summary}

We have presented an objective PCA-based framework for examining the spatial and temporal variability of DSDs and applied it to a large dataset spanning from the deep tropics to the high latitudes. We used PCA to examine comprehensive modes of variability between quantities describing DSDs derived from disdrometers. Importantly, the leading two EOFs revealed the same covariance in all datasets (Fig. 3) despite differences in breadth of individual DSD parameters (Fig. 2). Based on the PCA analysis, six different groups of points with similar DSD characteristics were designated. However, the physical nature of these six DSD populations varied as a function of latitude, indicating that the processes contributing to the formation of each group may have different underlying physics.

In the low latitudes, groups 1 and 2 (roughly associated with the positive and negative modes of EOF1, respectively), showed surprising conformity to the previously identified convective-stratiform lines proposed by BR09 and T15 (Figs. 6a-c). Group 1 is exclusively associated with $R>10 \mathrm{~mm} \mathrm{~h}^{-1}$ at the prescribed $\sigma_{1.5}$ thresholds (Figs. 7d-f) and is characterized by significant ETH and strong reflectivities above the melting layer (Fig. 8), further supporting the convective nature of this population (Tokay et al. 1999; Atlas et al. 2000; Yuter and Houze 2002). The low latitudes have a pronounced population of points with moderate mean drop sizes $(1.5-2 \mathrm{~mm})$ and $\operatorname{large} \log N_{w}(>4)$, which mathematically emerge from PCA as having both high PC1 and high PC2 values (group 5), a feature that is suppressed in the mid- and high latitudes. These points yield some of the highest rain rates, have the highest drop concentrations, exhibit high reflectivities in the warm layer (Figs. 9, 10), and have ETH above the environmental melting level but below groups 1 and 6 (Figs. $8 \mathrm{~g}-\mathrm{i}$ ). We postulate this characteristic DSD is associated with warm rain processes and prolific collision-coalescence, where large LWC and deep warm cloud depths facilitate collisioncoalescence growth. In low $R\left(<10 \mathrm{~mm} \mathrm{~h}^{-1}\right)$, many previous studies have grappled with the difficulty in separating convective and stratiform processes because of the similarities and overlap in DSD parameters in 2D space (Tokay and Short 1996; Yuter and Houze 1997). This is evident in the overlap between groups 2 and 3 

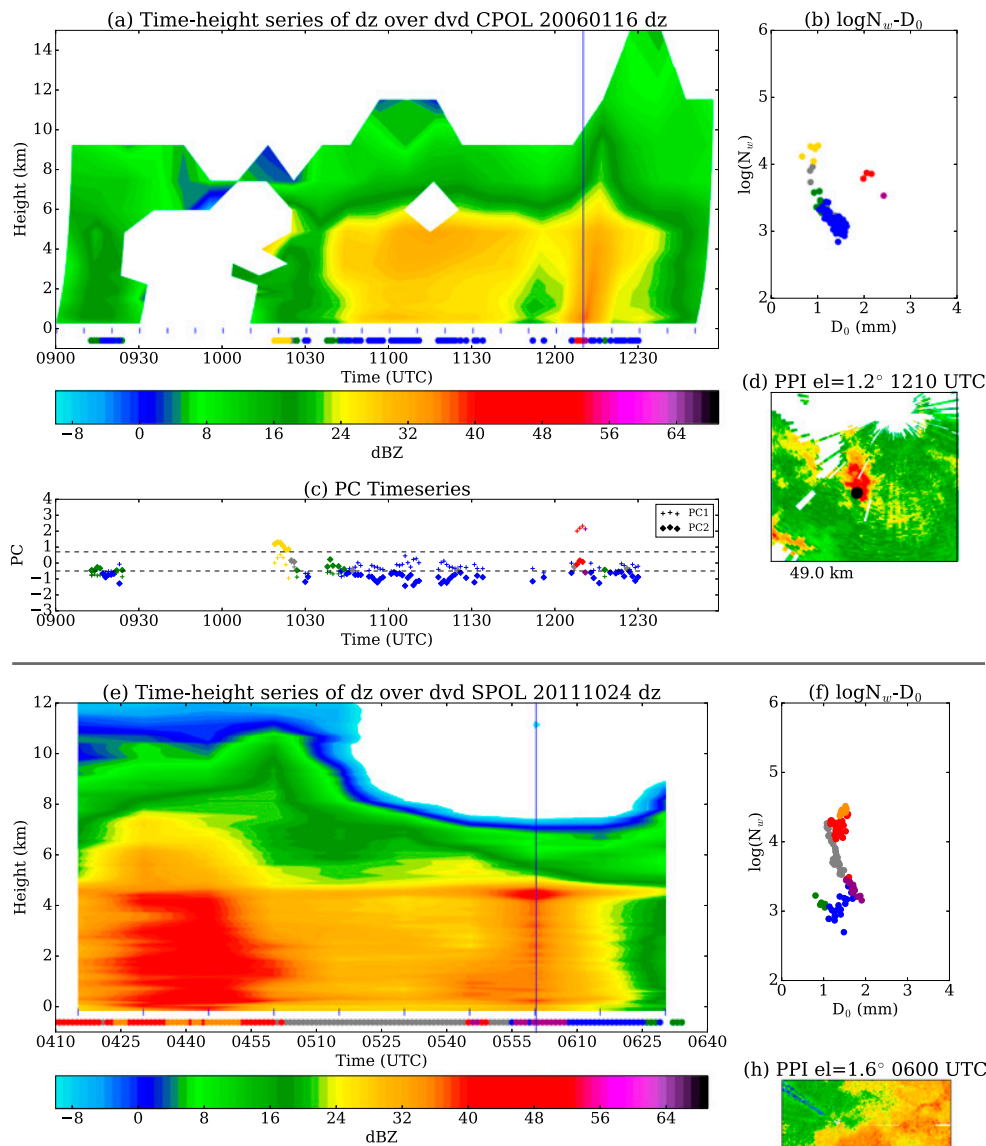

(g) PC Timeseries

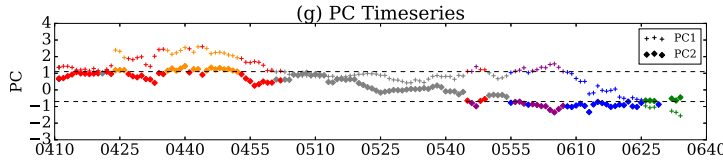

(h) PPI el $=1.6^{\circ} 0600$ UTC
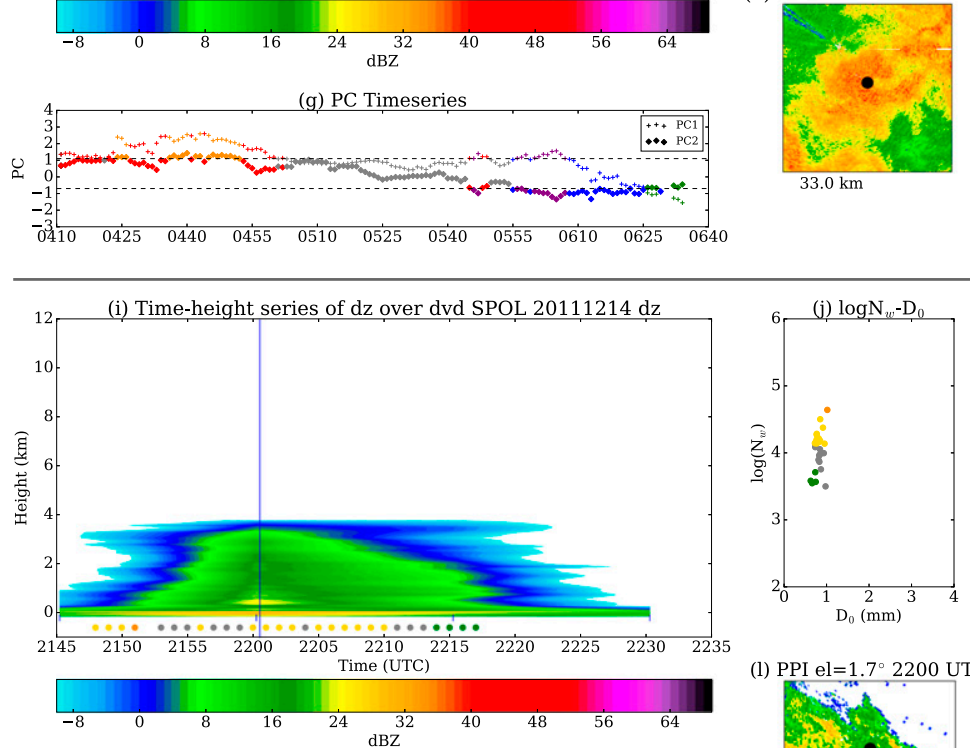

(k) PC Timeseries
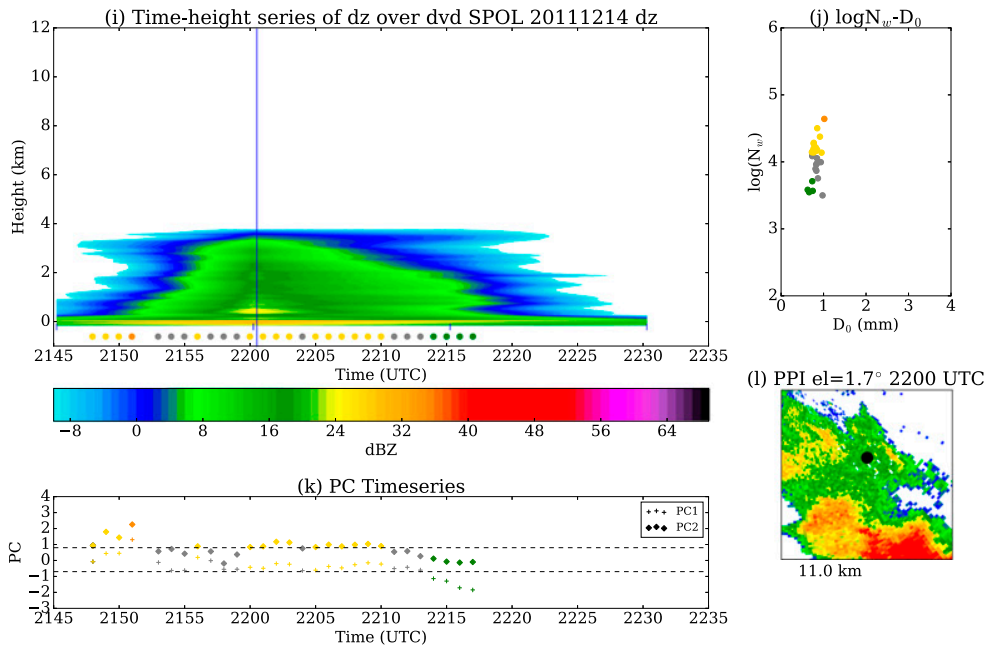

FIG. 9. Time-height cross sections constructed from (a) C-band polarimetric (CPOL) PPI data from Darwin and (e),(i) S-band polarimetric (SPOL) RHI data from Gan Island. Radar reflectivity is color contoured in (a), (d), (e), (h), (i), and (l), where (d), (h), and (l) represent a PPI at the time of the vertical line and the 
(Figs. 6, 7), which have similar ranges of $\mu$ and $D_{0}$ values. However, PCA allows for covariance in multiple dimensions, thereby providing a more robust separation between groups 2 and 3 through differing $N_{w}$, LWC, and $N_{t}$ (Fig. 5b). Group 3 is associated with a large population of points with very small median sizes but numerous drops. Radar analysis revealed that the radar echoes producing the surface DSD observations for group 3 are shallow and weak in all three latitude locations. Perhaps in these cases, the physical depth of the cloud is insufficient to support coalescence (Berry and Reinhardt 1974; Cotton et al. 2010; Lau and Wu 2003).

In the midlatitudes, a significant number of points are associated with large $D_{0}$ but $\operatorname{low} \log N_{w}$, which fall into groups 4 and 6. However, while group 4 has $R$ and LWC values that do not stray far from the global mean of $\sim 4 \mathrm{~mm} \mathrm{~h}^{-1}$ and $0.23 \mathrm{~g} \mathrm{~m}^{-3}$, group 6 has comparably large deviations of these quantities, indicating significant LWC coupled with large drops ( $D_{0}$ up to $5 \mathrm{~mm}$ ). This could indicate convective ice processes and/or continued coalescence in the warm cloud within group 6 . Group 1 in the midlatitudes has a lower mean $\log N_{w}$ and higher mean $D_{0}$ compared to the low latitudes (Tables 3-4), consistent with the maritime and continental regimes described by BR03. Radar analysis revealed larger mean reflectivities aloft and higher ETH, as well as very large (1.5 dB) mean $Z_{\mathrm{dr}}$ (Fig. 8).

The high latitudes are notable for the significant population of points with small $D_{0}(0.68 \mathrm{~mm})$, high $\log N_{w}$ (4.81), and high $\mu$ (6.75; Tables 3-5). Many of these points are captured by the variability distinguished in group 3. It is clear that the T15 C-S separation line developed for the tropical ocean is not applicable to the high latitudes (nor was it intended to be), as it cuts directly through the highest density of points in $\log N_{w}-D_{0}$ space in the high latitudes (Fig. 2c). Group 5 is notably absent, while groups 1 and 6 are limited in $\log N_{w}-D_{0}$ space, suggesting that there may be differences in the microphysical processes shaping the surface DSD despite sharing commonalities with the convective populations in the mid- and low latitudes.
These DSD groupings have important implications for estimating rain rates from radar, as they result in a spectrum of $Z-R$ relationships (Figs. 7d-f). Group 2 features modest $Z$ but the smallest $R$ values, generally $<1 \mathrm{~mm} \mathrm{~h}^{-1}$ (at the $\sigma_{1.5}$ threshold). There is overlap with group 3, which tends to have larger $R$ and larger $Z$ because of the increased LWC and drop concentrations. Interestingly, group 1 points are associated with $R>10 \mathrm{~mm} \mathrm{~h}^{-1}$, a threshold considered to be exclusively convective precipitation based on earlier studies (e.g., Atlas et al. 2000; Yuter and Houze 2002). Most of the group 3 points have $R<10 \mathrm{~mm} \mathrm{~h}^{-1}$, although group 5 yields some of the highest $R$ values along with group 1 . It is interesting to note that group 3 spans a relatively narrow range of $Z-R$ relationships, particularly in the tropics (Fig. 7f) and similarly for group 5 . On the contrary, group 1 does not follow a distinct $Z-R$ relationship but is associated with both high $Z$ and high $R$ in all latitude bands. Groups 4 and 6 have much lower $R$ for a given $Z$ compared to the distributions of groups 3 and 5. Interestingly, there is increased scatter between $Z$ and $R$ with increasing latitude, and there is a larger fraction of ambiguous points that do not meet the $\sigma_{1.5}$ threshold, particularly for the light rain rates. It is possible that additional modes of DSD variability may be explained by the higher-order EOFs that are not described by the six groups derived from EOF1 and EOF2. It is also possible that more data from high-latitude, light-rain-rate conditions are needed in order to account for DSD variability in this regime. Thus, our analysis reveals important information about how the DSD variability relates to radar-based rainfall retrievals.

To summarize our findings, we present a conceptual model based on our group determination in $N_{w}-D_{0}$ space (Fig. 12). Groups 1, 3, 5, and 6 are characterized by convective precipitation processes, where particles are assumed to grow as they are lifted by a convective updraft then, after sufficient growth, fall back through the updraft growing to even larger sizes. We note that convection is a continuum, where group 5 represents convection dominated by warm rain processes, such as where warm cloud depths are especially deep,

disdrometer location denoted by a black dot. The reflectivity scale is the same as the time-height, and the approximate scale of the PPI is given at the bottom. The start times of the PPIs/RHIs used to construct the time-height cross sections are illustrated by hatch marks along $x=0$ in (a), (e), and (i). The disdrometer group classifications are shown as colored dots along the time series. (b),(f),(j) For reference, the disdrometer points are shown in $\log N_{w}-D_{0}$ space. Below the reflectivity time-height in (a), (e), and (i) are (c), (g), (k) the PC values as a time series, with the $\mathrm{PC}$ thresholds indicated by dashed horizontal lines. Note: for illustration purposes, the PC $\sigma$ threshold has been lowered to $\sigma_{1.0}$. 
(a) Time-height series of dz over sn37 NPOL 20130519

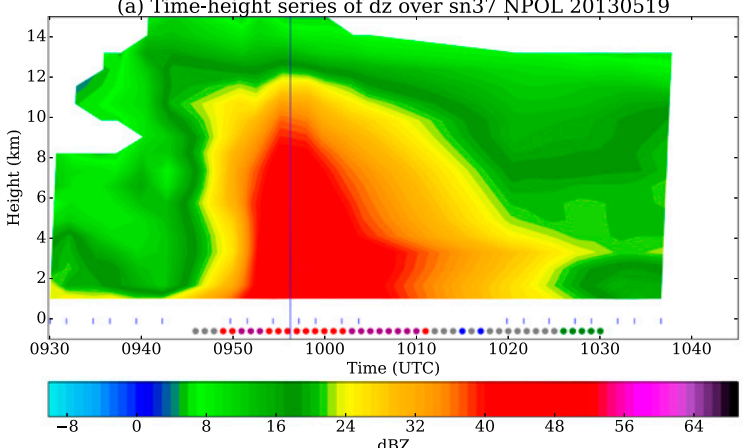

(c) PC Timeseries

u

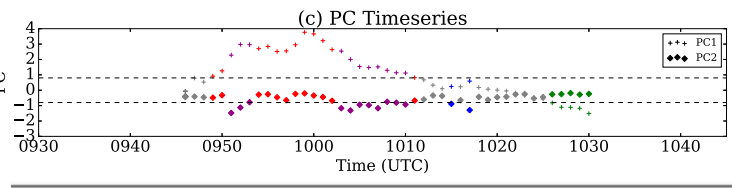

(e) Time-height series of dz over sn36 NPOL 20130509

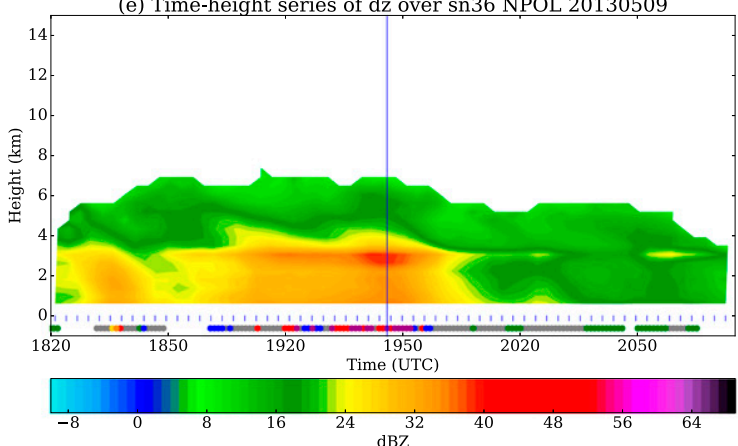

(g) PC Timeseries
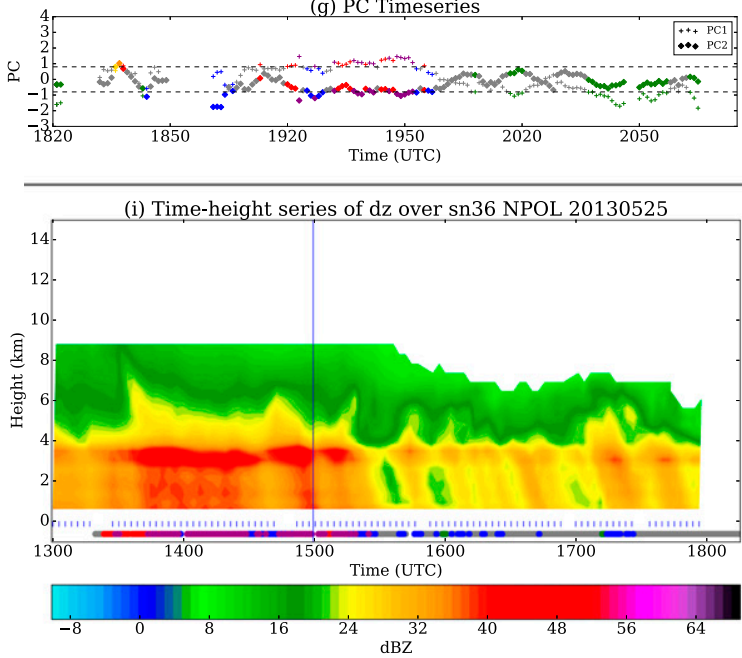

(k) PC Timeseries

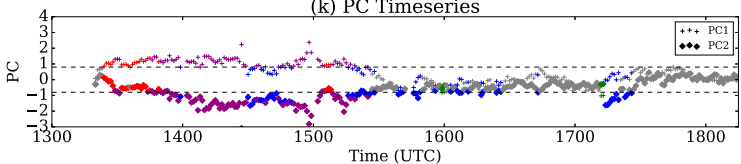

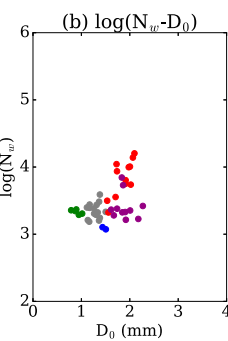

(d) el $=1.4^{\circ} 0956$ UTC

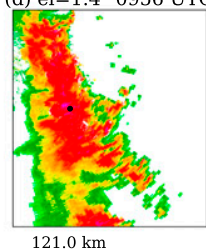

$121.0 \mathrm{~km}$
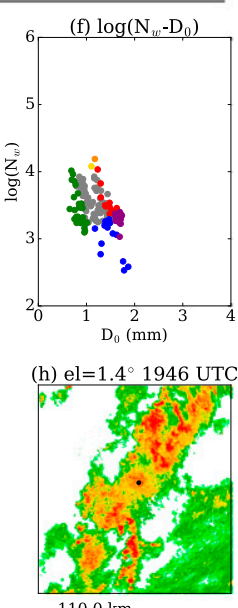

$110.0 \mathrm{~km}$
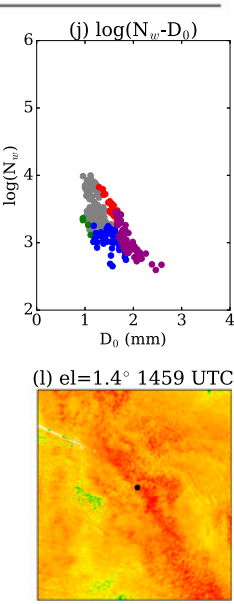

$110.0 \mathrm{~km}$

FIG. 10. As in Fig. 9, but time-height cross sections constructed from NASA polarimetric (NPOL) PPI data from IFloodS. 

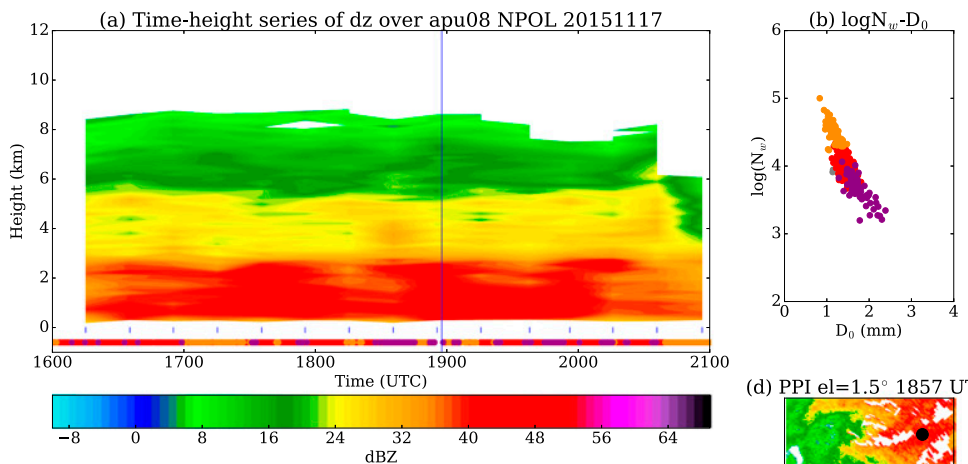

(d) PPI el $=1.5^{\circ} 1857$ UTC

(c) PC Timeseries
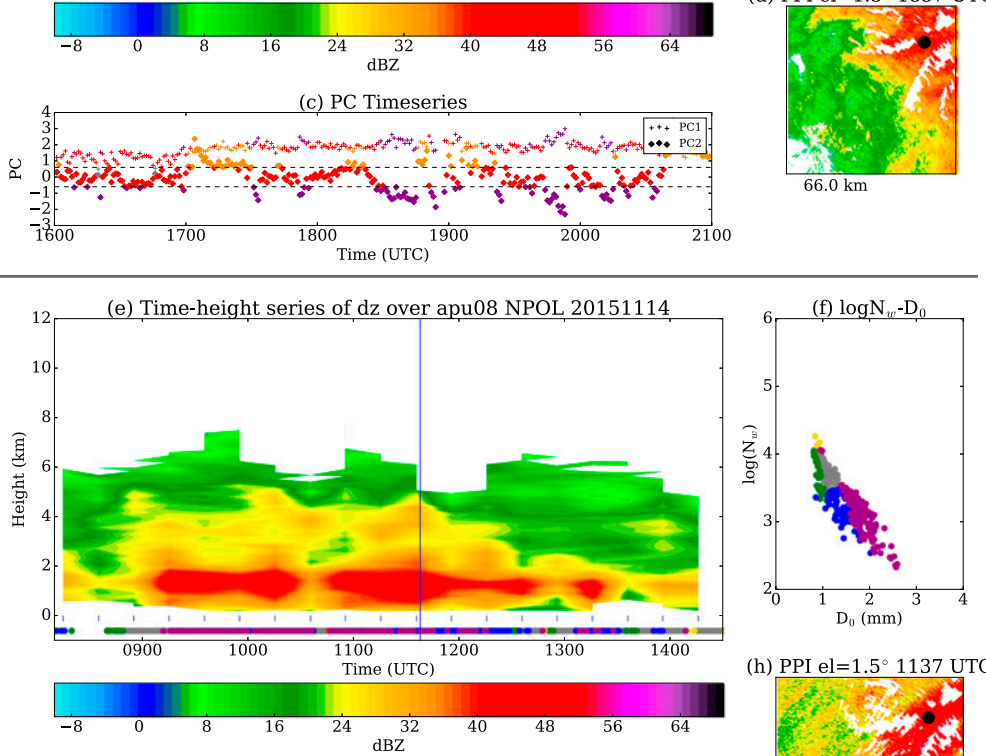

(g) PC Timeseries
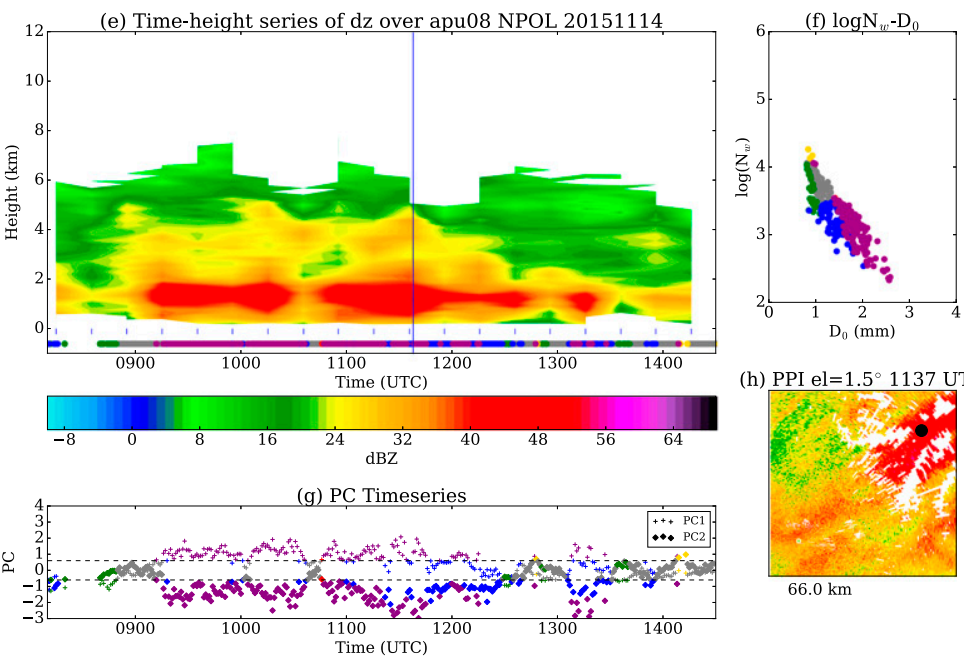

(h) PPI el=1.5 1137 UTC
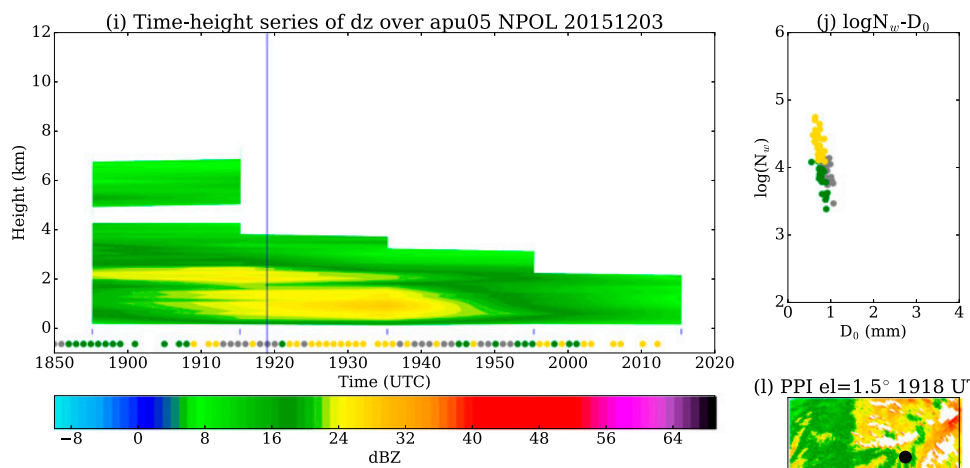

(k) PC Timeseries

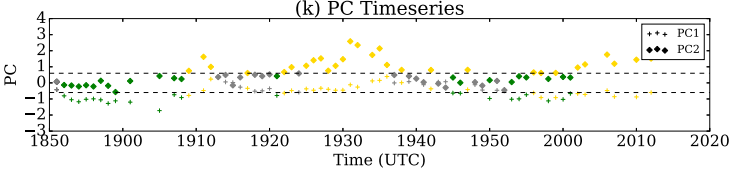

(l) PPI el $=1.5^{\circ} 1918$ UTC

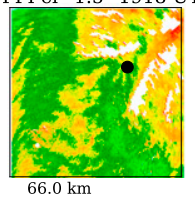

FIG. 11. As in Fig. 9, but time-height cross sections constructed from NPOL RHI data from OLYMPEX. 


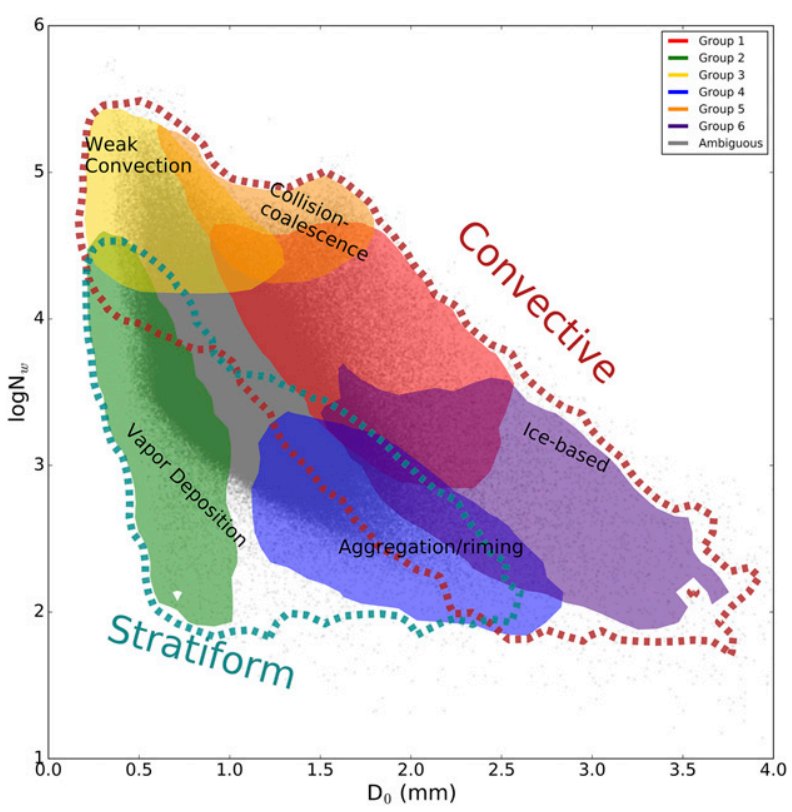

FIG. 12. Conceptual model illustrating the dominant mechanisms for the six groups objectively determined from the surface disdrometers using PCA in $\log N_{w}-D_{0}$ space. The gray dots represent every point in the global dataset. Solid contours represent smoothed Gaussian 1- $\sigma$ regions encompassing each of the six groups (determined using thresholds on PC1 and PC2 values), while inferred processes are in black. Dashed dark red and cyan contours represent groups related to convective and stratiform processes, respectively.

supporting enhanced growth by collision and coalescence. Group 6 is dominated by ice-based convective precipitation, indicated by large $D_{0}$ and $\operatorname{low} \log N_{w}$, where strong vertical motions support robust mixedphase production of graupel and possibly hail, leading to large raindrops at the surface owing to melting. Group 1 has some components of ice-based and warm rain growth processes. The progression from warm rain to ice-based processes in the convective group also follows the maritime/continental trends noted in previous studies (e.g., BR03; Ulbrich and Atlas 2007; BR09; T15). Groups 1, 5, and 6 generally conform to the C-S separation proposed by BR09 (Figs. 6a-c). Group 3 is also convective in nature, with numerous but small drops, shallow ETH, and generally weak reflectivities corresponding to warm rain showers. In the tropics, this group is associated with weak convective motions, but in a topographically forced location such as OLYMPEX, this may be a signature of orographic enhancement. Groups 2 and 4 are stratiform precipitation processes, with increasing $D_{0}$ and decreasing $N_{w}$ being correlated with brightband intensity, representing an evolution from melted vapor-grown particles to aggregation and riming processes. The light rain rates and small drop diameters associated with group 2, as well as the vertical profile of $Z$ and $Z_{\mathrm{dr}}$, indicate this group is weak stratiform precipitation with small- to modest-sized ice particles grown by vapor deposition entering the melting layer leading to brightband reflectivities only reaching 20-25 dBZ. Group 4 has much larger drop sizes but relatively $\operatorname{low} \log N_{w}$ (and also comparatively low drop concentrations), accompanied by a distinct radar-based signature of aggregation aloft, especially in the IFloodS data. In this group, small ice particles form aloft and undergo growth by deposition, followed by aggregation. Distinct and sharp radar bright bands $(>30 \mathrm{dBZ})$ form as the aggregates begin their initial stages of melting.

While the ultimate goal of this work was to link different global DSD modes to the physical processes shaping them, we recognize this is a complex problem with many different aspects including thermodynamic, microphysical, and dynamical feedbacks. To truly understand the variability in each region and the multitude of factors shaping the six DSD groups described herein requires synergistic modeling and observational studies. We have outlined a framework that allows for the statistical, objective separation of raining points by their DSD characteristics in six-dimensional space and have demonstrated that six distinct populations with similar characteristics can be grouped around the globe. While these populations vary in frequency and breadth across latitudes, they have important implications for radarbased rainfall retrieval and model assumptions surrounding rain and DSDs. An important continuation of the work will be to include environmental factors to understand their role in DSD variability. We also acknowledge the dataset may not have captured all rain regimes, and therefore, datasets from underrepresented locations (e.g., high-latitude oceans) should be considered in the future in order to more comprehensively address regional DSD variability. Seasonal and diurnal cycles of DSDs could also be examined from the multiyear datasets used in this study. Higher-order EOFs could be examined to identify more modes of variability.

Acknowledgments. We thank Dr. Merhala Thurai (CSU ECE) for her assistance in processing the disdrometer datasets and discussions about the analysis and Dr. Ali Tokay (NASA GSFC) for providing the NASA disdrometer datasets. We also thank Drs. Walt Petersen (NASA MSFC), Matt Schwaller, and Ramesh Kakar for their leadership of the NASA GV program. Joe Zagrodnik and Drs. Robert Houze and Lynn McMurdie (University of Washington) provided valuable insights for this work. Datasets were provided by NOAA Earth 
Science Research Laboratory; Australia's Bureau of Meteorology (BoM); NASA Global Hydrology Resource Center; and the Atmospheric Radiation Measurement (ARM) Climate Research Facility, a U.S. Department of Energy Office of Science user facility sponsored by the Office of Biological and Environmental Research. This work was supported by the DOE Atmospheric System Research program (DE-SC0014371), the NASA Precipitation Measurement Mission (PMM; NNX16AD85G), and the NASA PMM Ground Validation program (NNX16AI11G). The Python ARM Radar Toolkit (Py-ART) was used in the analysis performed herein (Helmus and Collis 2016). We also thank two anonymous reviewers and Dr. Joe Munchak for constructive comments that improved the analysis.

\section{REFERENCES}

Ackerman, T. P., and G. Stokes, 2003: The Atmospheric Radiation Measurement Program. Phys. Today, 56, 38-45, https:// doi.org/10.1063/1.1554135.

Atlas, D., and C. W. Ulbrich, 2000: An observationally based conceptual model of warm oceanic convective rain in the tropics. J. Appl. Meteor., 39, 2165-2181, https://doi.org/ 10.1175/1520-0450(2001)040<2165:AOBCMO>2.0.CO;2.

, — , F. D. Marks Jr., E. Amitai, and C. R. Williams, 1999: Systematic variation of drop size and radar-rainfall relations. J. Geophys. Res., 104, 6155-6169, https://doi.org/10.1029/ 1998JD200098.

,,,--- R. A. Black, E. Amitai, P. T. Willis, and C. E. Samsury, 2000: Partitioning tropical oceanic convective and stratiform rains by draft strength. J. Geophys. Res., 105, 22592267, https://doi.org/10.1029/1999JD901009.

Barros, A. P., and Coauthors, 2014: The GPM GV Integrated Precipitation and Hydrology Experiment (IPHEx) in the southern Appalachians-Focus on water cycle processes. 2014 Fall Meeting, San Francisco, CA, Amer. Geophys. Union, Abstract H11M-04.

Battaglia, A., E. Rustemeier, A. Tokay, U. Blahak, and C. Simmer, 2010: PARSIVEL snow observations: A critical assessment. J. Atmos. Oceanic Technol., 27, 333-344, https://doi.org/ 10.1175/2009JTECHA1332.1.

Battan, L. J., 1973: Radar Observation of the Atmosphere. University of Chicago Press, 324 pp.

Berry, E. X., and R. L. Reinhardt, 1974: An analysis of cloud drop growth by collection: Part I. Double distributions. J. Atmos. Sci., 31, 1814-1824, https://doi.org/10.1175/1520-0469(1974)031<1814: $\mathrm{AAOCDG}>2.0 . \mathrm{CO} ; 2$.

Bringi, V. N., and V. Chandrasekar, 2001: Polarimetric Doppler Weather Radar: Principles and Applications. Cambridge University Press, 636 pp.

,-- J. Hubbert, E. Gorgucci, W. L. Randeu, and M. Schönhuber, 2003: Raindrop size distribution in different climatic regimes from disdrometer and dual-polarized radar analysis. J. Atmos. Sci., 60, 354-365, https://doi.org/10.1175/ 1520-0469(2003)060<0354:RSDIDC $>2.0 . C O ; 2$.

, C. R. Williams, M. Thurai, and P. T. May, 2009: Using dualpolarized radar and dual-frequency profiler for DSD characterization: A case study from Darwin, Australia. J. Atmos. Oceanic Technol., 26, 2107-2122, https://doi.org/10.1175/2009JTECHA1258.1.
— , G.-J. Huang, S. J. Munchak, C. D. Kummerow, D. A. Marks, and D. B. Wolff, 2012: Comparison of drop size distribution parameter $\left(D_{0}\right)$ and rain rate from S-band dual-polarized ground radar, TRMM precipitation radar (PR), and combined PR-TMI: Two events from Kwajalein Atoll. J. Atmos. Oceanic Technol., 29, 1603-1616, https://doi.org/10.1175/JTECHD-11-00153.1.

Carr, N., P. E. Kirstetter, J. J. Gourley, and Y. Hong, 2017: Polarimetric signatures of midlatitude warm-rain precipitation events. J. Appl. Meteor. Climatol., 56, 697-711, https://doi.org/ 10.1175/JAMC-D-16-0164.1.

Cotton, W. R., G. Bryan, and S. C. van den Heever, 2010: Storm and Cloud Dynamics. Vol. 99, Academic Press, 809 pp.

,-- , and,- 2011 : Cumulonimbus clouds and severe convective storms. Storm and Cloud Dynamics-The Dynamics of Clouds and Precipitating Mesoscale Systems, W. R. Cotton, G. Bryan, and S. van den Heever, Eds., International Geophysics Series, Vol. 99, Academic Press, 315-454, https:// doi.org/10.1016/S0074-6142(10)09914-6.

Hannachi, A., I. Jolliffe, and D. Stephenson, 2007: Empirical orthogonal functions and related techniques in atmospheric science: A review. Int. J. Climatol., 27, 1119-1152, https:// doi.org/10.1002/joc.1499.

Helmus, J. J., and S. M. Collis, 2016: The Python ARM Radar Toolkit (Py-ART), a library for working with weather radar data in the Python programming language. J. Open Res. Software, 4, p.e25, https://doi.org/10.5334/jors.119.

Hou, A. Y., and Coauthors, 2014: The Global Precipitation Measurement Mission. Bull. Amer. Meteor. Soc., 95, 701-722, https://doi.org/10.1175/BAMS-D-13-00164.1.

Houze, R. A., Jr., 1997: Stratiform precipitation in regions of convection: A meteorological paradox? Bull. Amer. Meteor. Soc., 78, 2179-2196, https://doi.org/10.1175/1520-0477(1997)078<2179: SPIROC $>2.0 . \mathrm{CO} ; 2$.

— (OLYMPEX). Bull. Amer. Meteor. Soc., 98, 2167-2188, https://doi.org/10.1175/BAMS-D-16-0182.1.

Jensen, M. P., and Coauthors, 2015: The Midlatitude Continental Convective Clouds Experiment (MC3E). Bull. Amer. Meteor. Soc., 97, 1667-1686, https://doi.org/10.1175/BAMS-D-14-00228.1.

Joss, J., and A. Waldvogel, 1967: Ein Spektograph für Niederschlagstopfen mit automatischer Auswertung. Pure Appl. Geophys., 68, 240-246, https://doi.org/10.1007/BF00874898.

Kennedy, P. C., and S. A. Rutledge, 2011: S-band dual-polarization radar observations of winter storms. J. Appl. Meteor. Climatol., 50, 844-858, https://doi.org/10.1175/2010JAMC2558.1.

Kumjian, M. R., and O. Prat, 2014: The impact of raindrop collisional processes on the polarimetric radar variables. J. Atmos. Sci., 71, 3052-3067, https://doi.org/10.1175/JAS-D-13-0357.1.

Larsen, M. L., and K. A. O'Dell, 2016: Sampling variability effects in drop-resolving disdrometer observations. J. Geophys. Res. Atmos., 121, 11 777-11 791, https://doi.org/10.1002/2016JD025491.

Lau, K.-M. and H. T. Wu, 2003: Warm rain processes over tropical oceans and climate implications. Geophys. Res. Lett., 30, 2290 , https://doi.org/10.1029/2003GL018567.

L'Ecuyer, T., W. A. Petersen, and D. N. Moisseev, 2010: Light Precipitation Validation Experiment (LPVEx): Overview and results. 2010 Fall Meeting, San Francisco, CA, Amer. Geophys. Union, Abstract A13K-02.

Long, C. N., and Coauthors, 2011: ARM MJO investigation experiment on Gan Island (AMIE-Gan) science plan. ARM Tech. Rep. DOE/SC-ARM-11-005, 63 pp., https://www.arm. gov/publications/programdocs/doe-sc-arm-11-005.pdf. 
May, P. T., J. H. Mather, G. Vaughan, C. Jakob, G. M. McFarquhar, K. N. Bower, and G. G. Mace, 2008: The Tropical Warm Pool International Cloud Experiment. Bull. Amer. Meteor. Soc., 89, 629-646, https://doi.org/10.1175/BAMS-89-5-629.

Meyers, M. P., R. L. Walko, J. Y. Harrington, and W. R. Cotton, 1997: New RAMS cloud microphysics parameterization. Part II: The two-moment scheme. Atmos. Res., 45, 3-39, https:// doi.org/10.1016/S0169-8095(97)00018-5.

Milbrandt, J. A., and M. K. Yau, 2005: A multimoment bulk microphysics parameterization. Part I: Analysis of the role of the spectral shape parameter. J. Atmos. Sci., 62, 3051-3064 https://doi.org/10.1175/JAS3534.1.

Munchak, S. J., C. D. Kummerow, and G. Elsaesser, 2012: Relationships between the raindrop size distribution and properties of the environment and clouds inferred from TRMM. J. Climate, 25, 2963-2978, https://doi.org/10.1175/JCLI-D-11-00274.1.

Petäjä, T., and Coauthors, 2016: BAECC: A field campaign to elucidate the impact of biogenic aerosols on clouds and climate. Bull. Amer. Meteor. Soc., 97, 1909-1928, https://doi.org/ 10.1175/BAMS-D-14-00199.1.

Petersen, W. and P. Gatlin, 2013: GPM ground validation twodimensional video disdrometer (2DVD) IFloodS. NASA EOSDIS Global Hydrology Resource Center Distributed Active Archive Center, accessed 5 September 2014, https:// doi.org/10.5067/GPMGV/IFLOODS/2DVD/DATA301.

—, and —, 2014: GPM ground validation two-dimensional video disdrometer (2DVD) IPHEx. NASA EOSDIS Global Hydrology Resource Center Distributed Active Archive Center, accessed 14 September 2014, https://doi.org/10.5067/ GPMGV/IPHEX/2DVD/DATA301.

- L. Carey, V. N. Bringi, A. Tokay, and P. Gatlin, 2010: GPM ground validation two-dimensional video disdrometer (2DVD) LPVEx. NASA EOSDIS Global Hydrology Resource Center Distributed Active Archive Center, accessed 13 January 2011, https://doi.org/10.5067/GPMGV/LPVEX/2DVD/DATA301.

,,,--- , and,- 2011 : GPM ground validation two-dimensional video disdrometer (2DVD) MC3E. NASA EOSDIS Global Hydrology Resource Center Distributed Active Archive Center, accessed 11 December 2011, https:// doi.org/10.5067/GPMGV/MC3E/2DVD/DATA301.

Petty, G. W., and W. Huang, 2011: The modified gamma size distribution applied to inhomogeneous and nonspherical particles: Key relationships and conversions. J. Atmos. Sci., 68 1460-1473, https://doi.org/10.1175/2011JAS3645.1.

Price, C., and D. Rind, 1993: What determines the cloud-to-ground lightning fraction in thunderstorms? Geophys. Res. Lett., 20, 463-466, https://doi.org/10.1029/93GL00226.

Rutledge, S. A., and R. A. Houze Jr., 1987: A diagnostic modeling study of the trailing stratiform region of a midlatitude squall line. J. Atmos. Sci., 44, 2640-2656, https://doi.org/10.1175/ 1520-0469(1987)044<2640:ADMSOT>2.0.CO;2.

Ryzhkov, A., P. Zhang, H. Reeves, M. Kumjian, T. Tschallener, S. Trömel, and C. Simmer, 2016: Quasi-vertical profiles-A new way to look at polarimetric radar data. J. Atmos. Oceanic Technol., 33, 551-562, https://doi.org/10.1175/JTECH-D-150020.1.

Saleeby, S. M., and W. R. Cotton, 2004: A large-droplet mode and prognostic number concentration of cloud droplets in the Colorado State University Regional Atmospheric Modeling System (RAMS). Part I: Module descriptions and supercell test simulations. J. Appl. Meteor., 43, 182-195, https://doi.org/ 10.1175/1520-0450(2004)043<0182:ALMAPN >2.0.CO;2.
Schönhuber, M., G. Lammer, and W. L. Randeu, 2008: The 2Dvideo-disdrometer. Precipitation: Advances in Measurement, Estimation and Prediction. S. Michaelides, Ed., Springer, 3-31, https://doi.org/10.1007/978-3-540-77655-0_1.

Seo, B.-C., B. Dolan, W. Krajewski, S. A. Rutledge, and W. A. Petersen, 2015: Comparison of single- and dual-polarizationbased rainfall estimates using NEXRAD data for the NASA Iowa Flood Studies project. J. Hydrometeor., 16, 1658-1675, https://doi.org/10.1175/JHM-D-14-0169.1.

Sheppard, B. E., and P. I. Joe, 1994: Comparison of raindrop size distribution measurements by a Joss-Waldvogel disdrometer, a PMS 2DG spectrometer, and a POSS Doppler radar. J. Atmos. Oceanic Technol., 11, 874-887, https://doi.org/ 10.1175/1520-0426(1994)011<0874:CORSDM>2.0.CO;2.

Smith, P. L., 2016: Sampling issues in estimating radar variables from disdrometer data. J. Atmos. Oceanic Technol., 33, 23052313, https://doi.org/10.1175/JTECH-D-16-0040.1.

— Z. Z. Liu, and J. Joss, 1993: A study of sampling-variability effects in raindrop size observations. J. Appl. Meteor., 32, 1259-1269, https:// doi.org/10.1175/1520-0450(1993)032<1259:ASOSVE>2.0.CO;2.

Thompson, E. J., S. A. Rutledge, B. Dolan, and M. Thurai, 2015: Drop size distributions and radar observations of convective and stratiform rain over the equatorial Indian and west Pacific Oceans. J. Atmos. Sci., 72, 4091-4125, https://doi.org/10.1175/ JAS-D-14-0206.1.

Thurai, M., V. N. Bringi, and P. T. May, 2010: CPOL radar-derived drop size distribution statistics of stratiform and convective rain for two regimes in Darwin, Australia. J. Atmos. Oceanic Technol., 27, 932-942, https://doi.org/10.1175/2010JTECHA1349.1.

W. A. Petersen, A. Tokay, C. Schultz, and P. Gatlin, 2011: Drop size distribution comparisons between Parsivel and 2-D video disdrometers. Adv. Geosci., 30, 3-9, https://doi.org/ 10.5194/adgeo-30-3-2011.

—, C. R. Williams, and V. N. Bringi, 2014: Examining the correlations between drop size distribution parameters using data from two side-by-side 2D-video disdrometers. Atmos. Res., 144, 95-110, https://doi.org/10.1016/j.atmosres.2014.01.002.

, P. Gatlin, V. N. Bringi, W. Petersen, P. Kennedy, B. Notaros, and L. Carey, 2017: Toward completing the raindrop size spectrum: Case studies involving 2D-video disdrometer, droplet spectrometer, and polarimetric radar measurements. J. Appl. Meteor. Climatol., 56, 877-896, https://doi.org/ 10.1175/JAMC-D-16-0304.1.

Tokay, A., and D. A. Short, 1996: Evidence from tropical rain drop spectra of the origin of rain from stratiform versus convective clouds. J. Appl. Meteor., 35, 355-371, https://doi.org/10.1175/ 1520-0450(1996)035<0355:EFTRSO >2.0.CO;2.

C. R. Williams, W. L. Ecklund, and K. S. Gage, 1999: Tropical rainfall associated with convective and stratiform clouds: Intercomparison of disdrometer and profiler measurements. J. Appl. Meteor., 38, 302-320, https://doi.org/ 10.1175/1520-0450(1999)038<0302:TRAWCA > 2.0.CO;2.

, A. Kruger, and W. Krajewski, 2001: Comparison of drop size distribution measurements by impact and optical disdrometers. J. Appl. Meteor., 40, 2083-2097, https://doi.org/ 10.1175/1520-0450(2001)040<2083:CODSDM >2.0.CO;2.

, L. P. D'Adderio, D. B. Wolff, and W. A. Petersen, 2016: A field study of pixel-scale variability of raindrop size distribution in the mid-Atlantic region. J. Hydrometeor., 17, 18551868, https://doi.org/10.1175/JHM-D-15-0159.1.

Uijlenhoet, R., M. Steiner, and J. A. Smith, 2003: Variability of raindrop size distributions in a squall line and implications 
for radar rainfall estimation. J. Hydrometeor., 4, 43-61, https:// doi.org/10.1175/1525-7541(2003)004<0043:VORSDI >2.0.CO;2.

Ulbrich, C. W., 1983: Natural variations in the analytical form of the raindrop size distribution. J. Climate Appl. Meteor., 22, 1764-1775, https://doi.org/10.1175/1520-0450(1983)022<1764: NVITAF $>2.0 . \mathrm{CO} ; 2$

, and D. Atlas, 2007: Microphysics of raindrop size spectra: Tropical continental and maritime storms. J. Appl. Meteor. Climatol., 46, 1777-1791, https://doi.org/10.1175/2007JAMC1649.1.

Williams, C. R., A. Kruger, K. S. Gage, A. Tokay, R. Cifelli, W. F. Krajewski, and C. Kummerow, 2000: Comparison of simultaneous rain drop size distributions estimated from two surface disdrometers and a UHF profiler. Geophys. Res. Lett., 27, 1763-1766, https://doi.org/10.1029/ 1999 GL011100.

- and Coauthors, 2014: Describing the shape of raindrop size distributions using uncorrelated raindrop mass spectrum parameters. J. Appl. Meteor. Climatol., 53, 1282-1296, https:// doi.org/10.1175/JAMC-D-13-076.1.

Willis, P. T., 1984: Functional fits to some observed drop size distributions and parameterization of rain. J. Atmos. Sci., 41, 1648-1661, https:// doi.org/10.1175/1520-0469(1984)041<1648:FFTSOD>2.0.CO;2.

Yuter, S. E., and R. A. Houze Jr., 1997: Measurements of raindrop size distributions over the Pacific warm pool and implications for $Z-R$ relations. J. Appl. Meteor., 36, 847-867, https://doi.org/ 10.1175/1520-0450(1997)036<0847:MORSDO > 2.0.CO;2.

$\longrightarrow$, and - 2002: Comment on "Partitioning tropical oceanic convective and stratiform rains by draft strength" by David Atlas et al. J. Geophys. Res., 107, 4005, https://doi.org/ 10.1029/2000JD000205.

, D. E. Kingsmill, L. B. Nance, and M. Löffler-Mang, 2006: Observations of precipitation size and fall speed characteristics within coexisting rain and wet snow. J. Appl. Meteor. Climatol., 45, 1450-1464, https://doi.org/10.1175/JAM2406.1. 